\title{
The tarsal taste of honey bees: behavioral and electrophysiological analyses
}

\section{Maria Gabriela de Brito Sanchez ${ }^{1,2 *}$, Esther Lorenzo ${ }^{1,2}$, Songkun Su ${ }^{3}$, Fanglin Liu ${ }^{4}$, Yi Zhan ${ }^{3}$ and Martin Giurfa ${ }^{1,2}$}

${ }^{1}$ Centre National de la Recherche Scientifique (CNRS), Research Center on Animal Cognition (UMR5169), Toulouse, France

2 University Paul-Sabatier, Research Center on Animal Cognition (UMR5169), Toulouse, France

${ }^{3}$ College of Animal Sciences, Zhejiang University, Hangzhou, China

${ }^{4}$ Xishuangbanna Tropical Botanical Garden, Chinese Academy of Sciences, Kunming, China

\section{Edited by:}

Carmen Sandi, Ecole Polytechnique

Federale De Lausanne, Switzerland

Reviewed by:

Judith Reinhard, University of

Queensland, Australia

Fernando J. Guerrieri, Univesité

François Rabelais Tours, France

*Correspondence:

Maria Gabriela de Brito Sanchez, Centre de Recherches sur la

Cognition Animale, Building 4R3,

Université de Toulouse, 31062

Toulouse Cedex 9, France

e-mail: maria.de-brito-sanchez@ univ-t/se3.fr
Taste plays a crucial role in the life of honey bees as their survival depends on the collection and intake of nectar and pollen, and other natural products. Here we studied the tarsal taste of honey bees through a series of behavioral and electrophysiological analyses. We characterized responsiveness to various sweet, salty and bitter tastants delivered to gustatory sensilla of the fore tarsi. Behavioral experiments showed that stimulation of opposite fore tarsi with sucrose and bitter substances or water yielded different outcomes depending on the stimulation sequence. When sucrose was applied first, thereby eliciting proboscis extension, no bitter substance could induce proboscis retraction, thus suggesting that the primacy of sucrose stimulation induced a central excitatory state. When bitter substances or water were applied first, sucrose stimulation could still elicit proboscis extension but to a lower level, thus suggesting central inhibition based on contradictory gustatory input on opposite tarsi. Electrophysiological experiments showed that receptor cells in the gustatory sensilla of the tarsomeres are highly sensitive to saline solutions at low concentrations. No evidence for receptors responding specifically to sucrose or to bitter substances was found in these sensilla. Receptor cells in the gustatory sensilla of the claws are highly sensitive to sucrose. Although bees do not possess dedicated bitter-taste receptors in the tarsi, indirect bitter detection is possible because bitter tastes inhibit sucrose receptor cells of the claws when mixed with sucrose solution. By combining behavioral and electrophysiological approaches, these results provide the first integrative study on tarsal taste detection in the honey bee.

Keywords: taste, gustation, gustatory receptors, insect, honey bee, tarsi, proboscis extension reflex, electrophysiology

\section{INTRODUCTION}

Taste is a fundamental sensory modality for individual survival as it allows discriminating edible from non-edible items, which may cause significant harm or death (Scott, 2004, 2005; Yarmolinsky et al., 2009; Carleton et al., 2010; De Brito Sanchez and Giurfa, 2011). In the definition adopted throughout this work, taste is a specific form of contact chemoreception relying on specialized receptor neurons (gustatory receptor neurons or GRNs) tuned to respond to different kinds of substances in a food-related context. Not all contact chemoreceptors intervene in a food-related context, and are not, therefore, GRNs. For instance, contact chemoreceptors may be tuned to detect pheromone or kairomone compounds.

Insects, in particular the fruit fly Drosophila melanogaster, constitute powerful models for the study of the physiological principles of taste perception (Thorne et al., 2004; Hallem et al., 2006; Cobb et al., 2009; Montell, 2009). In insects, GRNs are primary neurons that are contained within cuticular structures called gustatory or taste sensilla (Dahanukar et al., 2005; Hallem et al., 2006). These sensilla contain two to four GRNs, one mechanosensory neuron and several types of accessory cells. Gustatory sensilla are not restricted to the region around the mouth but are usually distributed over different regions of the body surface and appendages such as the antennae, mouth parts, leg tarsi, and margins of the wings. Molecular gustatory receptors (Grs) located on the membrane of GRNs confer taste specificity and mediate appropriate responses to tastes (Dahanukar et al., 2005; Vosshall and Stocker, 2007; Cobb et al., 2009; Montell, 2009). In the fruit fly, 68 Grs encoded by 60 genes through alternative splicing have been identified (Clyne et al., 2000; Dunipace et al., 2001; Scott et al., 2001; Robertson et al., 2003). Some Grs have been linked to specific sweet and bitter tastants (Ishimoto and Tanimura, 2004; Thorne et al., 2004; Montell, 2009).

Yet, the sequencing of other insect genomes has shown that the taste organization of the fruit fly is not shared by all insects as different life styles led to modifications of the gustatory repertoire. In the honey bee Apis mellifera, which has a model status for research on learning, memory, and perception (Giurfa, 2007; Galizia et al., 2011), only 10 Grs were identified in the genome (The Honeybee Genome Sequencing Consortium, 2006). None 
of them shares homologies with bitter-tuned Grs of Drosophila, a finding that was interpreted as the result of taste specialization on sweet and non-toxic tastants (Robertson and Wanner, 2006). Until now, the specific tastants of these Grs remain unknown.

Behavioral and electrophysiological approaches have been used to characterize taste perception in bees (review in De Brito Sanchez, 2011). Sensitivity to sugars and saline solutions was found at the level of the antennae and mouth parts both in behavioral experiments and in electrophysiological recordings of single sensilla (Whitehead and Larsen, 1976a,b; Whitehead, 1978; Haupt, 2004; De Brito Sanchez et al., 2005). Interestingly, no sensitivity to bitter substances could be detected (De Brito Sanchez et al., 2005; Ayestaran et al., 2010), even if some bitter substances inhibit the response of sucrose GRNs when mixed with sucrose solution (De Brito Sanchez et al., 2005).

Despite their long-claimed role in gustation (Frings and Frings, 1949), the gustatory sensitivity of the honey bee foretarsi have remained mostly unexplored (De Brito Sanchez, 2011). Here we provide the first extensive account of honey bee tarsal gustation and characterized behavioral and electrophysiological responses to sweet, bitter, and saline substances at the level of these appendages.

\section{MATERIALS AND METHODS}

Free-flying honey bee foragers (female workers), Apis mellifera, were caught in the morning of every experimental day upon return to the hive entrance. They were placed in glass vials and cooled in ice until they stopped moving. They were then prepared in the laboratory for behavioral or electrophysiological experiments.

\section{BEHAVIORAL EXPERIMENTS Insects}

Bees were mounted individually in small metal tubes from which only their head and fore-tarsi protruded (De Brito Sanchez et al., 2008). The forelegs were fixed wide open in order to facilitate their stimulation (Figure 1A). The insects were kept for $2 \mathrm{~h}$ in a dark and humid container before the experiments. The antennae were amputated (Figure 1A) in order to avoid antennal interference in trials in which two gustatory stimuli had to be delivered on left and right fore-tarsi (De Brito Sanchez et al., 2008). Amputation occurred at least 2-3 h before experiments. Both antennae were cut with fine scissors at the base of the scapus, taking care not to pull them. Bees with leaking hemolymph were eliminated from the analysis (De Brito Sanchez et al., 2008).

Each subject was checked for intact PER before starting the experiments. This was done by lightly touching the fore tarsi with a toothpick soaked with sucrose solution $1 \mathrm{M}$ without subsequent feeding. Care was taken to ensure that the toothpick contacted both the tarsus and the claws (Figure 1). Extension of the proboscis beyond a virtual line between the open mandibles was counted as PER. Animals that did not show the reflex were discarded. Gustatory stimuli were delivered by means of a toothpick soaked in the solution tested. A different toothpick was used for each solution tested.

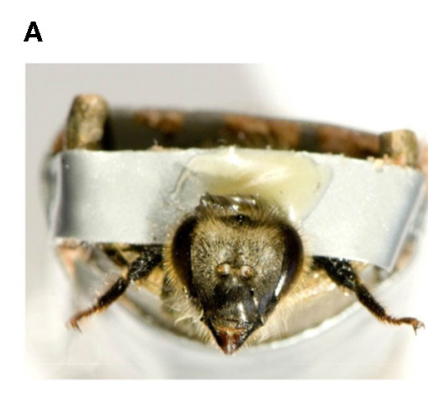

B
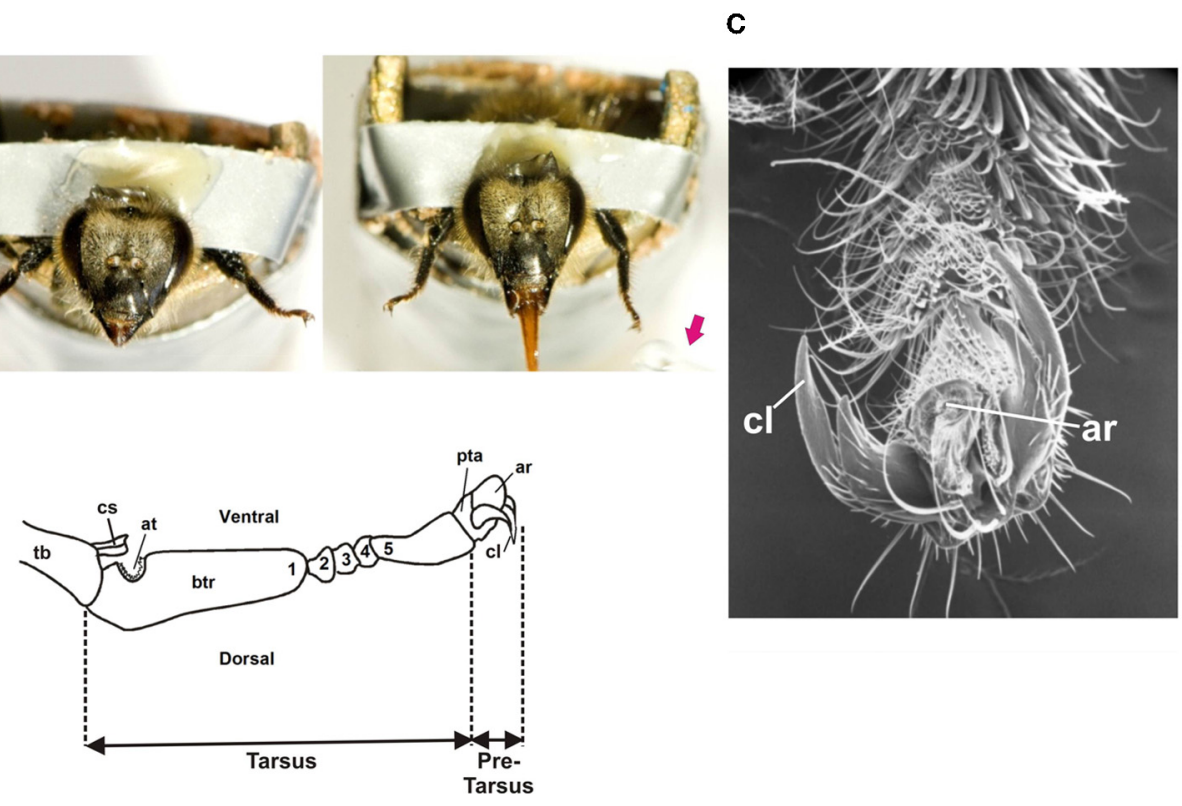

FIGURE 1 | (A) Left: Honey bee with amputated antennae harnessed in a metal tube with its forelegs fixed wide open in order to allow tarsal gustatory stimulation. Right: Proboscis extension reflex (PER) upon tarsal stimulation with a drop of sucrose solution (red arrow) delivered to the left tarsus. (B) Scheme of the distal segments of a honey bee foreleg showing the tarsus and the pretarsus. The tarsus has five tarsomeres: a basitarsus (btr: 1), which is the largest tarsomere, and 4 smaller tarsomeres (2-5). The basitarsus presents a notch of antenna cleaner (at) and the tibia (Tb) a closing spine (cs). The distally situated pretarsus (pta) bears a pair of lateral bifid claws (cl) and an arolium (ar), a small pad used to increase adhesion. (C) Detail of the pretarsus (pta) of a foreleg: cl: claws; ar: arolium. 


\section{Stimuli}

The gustatory stimuli employed in behavioral experiments were distilled water, sucrose $1 \mathrm{M}$, quinine hydrochloride $(1 / 10 / 100 \mathrm{mM})$, salicin $(1 / 10 / 100 \mathrm{mM})$ and caffeine $(1 / 10 / 100 \mathrm{mM})$. All chemicals were obtained from Sigma-Aldrich (Saint-Quentin Fallavier, France).

\section{Experiment 1}

We determined whether bitter substances (quinine, salicin, or caffeine) applied on the fore-tarsi exert an inhibitory effect on proboscis extension reflex (PER), an appetitive response triggered by prior tarsal stimulation with sucrose solution $1 \mathrm{M}$ (Figure 2A). (Kuwabara, 1957; De Brito Sanchez et al., 2005). This sucrose concentration elicits consistent PER when applied to the bees' fore-tarsi (De Brito Sanchez et al., 2008). Bees with amputated antennae were stimulated along three trials with sucrose solution $1 \mathrm{M}$ on one fore-tarsus (either left or right) in order to elicit PER, and with quinine, salicin, or caffeine of different concentrations on the contralateral tarsus to determine whether these substances induce proboscis retraction due to their potential aversive nature (Dethier and Bowdan, 1992). Both the first stimulation with sucrose solution and the second stimulation with the bitter substance lasted $10 \mathrm{~s}$. The interstimulus interval was $5 \mathrm{~s}$ (onset-onset) (Figure 2A).

We measured the proboscis response during the first $5 \mathrm{~s}$ of sucrose stimulation of one fore-tarsus and during the consecutive $5 \mathrm{~s}$ in which the second stimulation was delivered to the opposite fore-tarsus (bitter substance). The latter period allowed determining whether or not bees retracted the proboscis. Measuring retraction during the last $5 \mathrm{~s}$ of bitter stimulation, in the absence of sucrose, would be inappropriate as retraction could occur simply due to the absence of sucrose and not as a consequence of the bitter stimulation itself.

Three concentrations of bitter substance were consecutively assayed along trials: 1, 10, and $100 \mathrm{mM}$. The latter corresponds to a highly saturated solution. This increasing sequence was chosen to avoid fast response saturation. To control for possible sensitization induced by sucrose solution, we performed three control trials interspersed between the three bitter-substance trials. In these control trials, bees were stimulated during $10 \mathrm{~s}$ with water on one fore-tarsus, and with a dry toothpick during $10 \mathrm{~s}$ on the contralateral fore-tarsus. The interstimulus interval was also $5 \mathrm{~s}$.
A

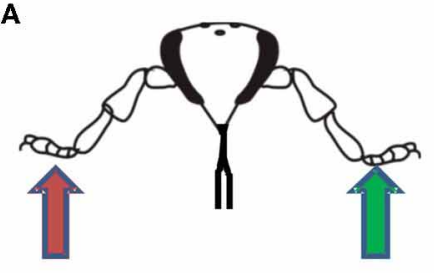

1) Sucrose

2) Bitter

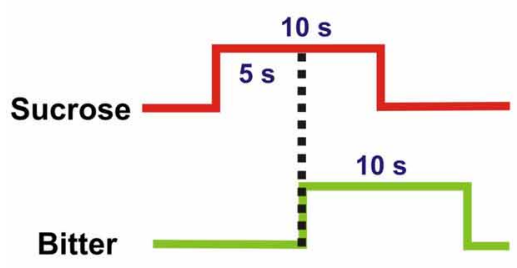

B

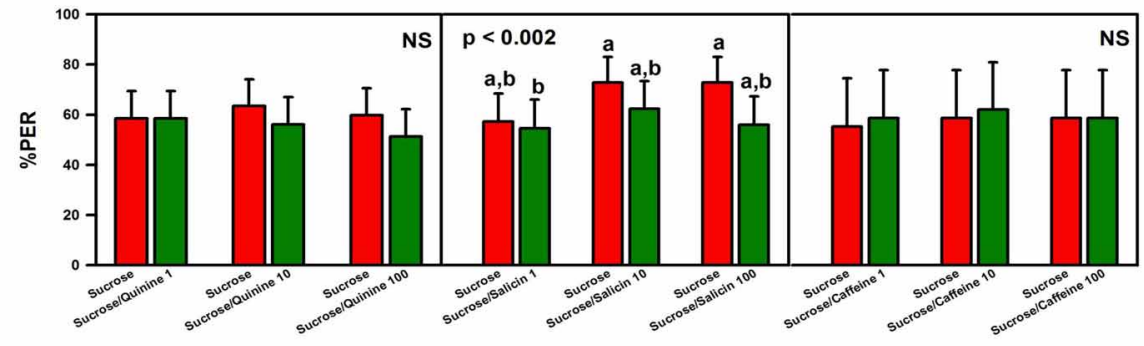

$\mathbf{E}$

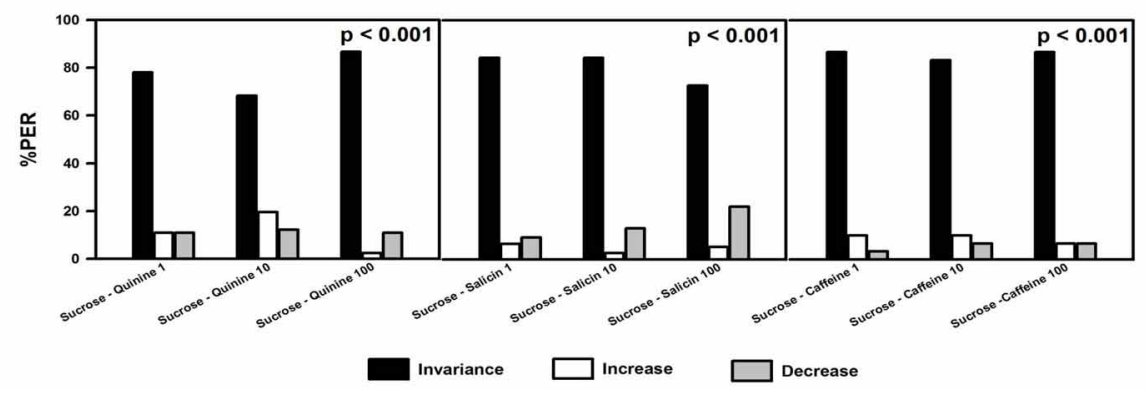

FIGURE 2 | Experiment 1. (A) Bees with amputated antennae were stimulated along three trials with sucrose solution $1 \mathrm{M}$ (red arrow; red trace) on one fore-tarsus (either left or right) in order to elicit PER, and $5 \mathrm{~s}$ later with quinine, salicin, or caffeine ("bitter", green arrow, green trace) of different concentrations on the contralateral tarsus to determine whether these substances induce proboscis retraction. (B) Percentage of proboscis extension responses (\% PER) upon stimulation with sucrose $1 \mathrm{M}$ (red bars) and quinine (1, 10, and $100 \mathrm{mM}$; green bars). (C) \% PER upon stimulation with sucrose $1 \mathrm{M}$ (red bars) and salicin (1, 10, and $100 \mathrm{mM}$; green bars). Different letters above bars indicate significant differences $(p<0.05)$. (D) \% PER upon stimulation with sucrose $1 \mathrm{M}$ (red bars) and caffeine
(1, 10, and $100 \mathrm{mM}$; green bars). (E) Percentage of bees into the invariance (black bars), increase (white bars), or decrease (gray bars) categories upon stimulation with sucrose $1 \mathrm{M}$ and quinine 1, 10, and $100 \mathrm{mM}$. "Decrease" means that sucrose induced PER and quinine induced retraction, "increase" means that sucrose did not induce PER but quinine did. "Invariance" means that no response change was induced by quinine with respect to sucrose. (F) Percentage of bees into the invariance, increase, or decrease categories upon stimulation with sucrose $1 \mathrm{M}$ and salicin 1, 10, and $100 \mathrm{mM}$. (G) Percentage of bees into the invariance, increase, or decrease categories upon stimulation with sucrose $1 \mathrm{M}$ and caffeine 1,10 , and $100 \mathrm{mM}$. 
For each bitter substance, two groups of bees were assayed: for one group, sucrose solution $1 \mathrm{M}$ or water was delivered on the right fore-tarsus and the bitter substance (quinine, salicin, or caffeine) or the dry toothpick on the left fore-tarsus; for the other group, stimulation sites were inversed. Experiments started with a control trial. Control and bitter-substance trials alternated so that each bee was subjected to six trials. The intertrial interval was $10 \mathrm{~min}$.

\section{Experiment 2}

We studied whether potential PER inhibition by a bitter substance (quinine or salicin) applied on one fore-tarsus can be overcome by sucrose solution $1 \mathrm{M}$ applied on the contralateral fore-tarsus (Figure 3A), thus resulting in PER (Dethier and Bowdan, 1992; Meunier et al., 2003). As in Experiment 1, we used bees with amputated antennae in order to avoid antennal interference (see above). An additional control was performed in which bees with intact antennae were used.

A 10 s stimulation with quinine or salicin solution was applied on one fore-tarsus, followed by a $10 \mathrm{~s}$ stimulation with sucrose on the contralateral fore-tarsus. The interstimulus interval was $5 \mathrm{~s}$ (onset-onset) (Figure 3A). Proboscis extension was quantified during the $5 \mathrm{~s}$ overlap of bitter and sucrose stimulation. Measuring it during the last $5 \mathrm{~s}$ of sucrose stimulation, in the absence of bitter stimulation, would be inappropriate as PER would occur simply in response to sucrose alone without overcoming any potential inhibition by the bitter substance.

Three concentrations of bitter substance were consecutively assayed along trials: 1,10 , and $100 \mathrm{mM}$. The latter corresponds to a highly saturated solution. This increasing sequence was chosen to avoid fast response saturation. To control for possible sensitization effects of sucrose solution, we performed three control trials that were interspersed between the three bitter-substance trials. In these control trials, bees were stimulated during $10 \mathrm{~s}$ with water on one fore-tarsus, and with a dry toothpick during $10 \mathrm{~s}$ on the contralateral fore-tarsus. The interstimulus interval was also 5 s. Experiments started always with a control trial. Control and bitter-substance trials alternated so that each bee was subjected to six trials. The intertrial interval was $10 \mathrm{~min}$.

Two groups of bees (both for antennae-amputated and intact bees) were treated in this way: for one group, the bitter substance (quinine or salicin) of a given concentration or water was delivered on the right fore-tarsus, and sucrose solution $1 \mathrm{M}$ or the dry toothpick on the left fore-tarsus; for the other group, stimulation sites were inversed.

\section{ELECTROPHYSIOLOGICAL EXPERIMENTS Insects}

Captured bees were placed in glass vials and cooled down on ice until they stopped moving. They were then mounted individually in Eppendorf tubes (Le Pecq, France) presenting a lateral slid through which a foreleg could be passed. The fixed bee was laid down horizontally, with the leg extended on a lateral support. The leg was fixed to the support by means of adhesive band tape in order to avoid movements. Bees fixed in this way were kept resting during $1 \mathrm{~h}$ before the start of the electrophysiological recordings.

\section{Recording sites}

The forelegs consist of six segments: the coxa, the trochanter, the femur, the tibia, the tarsus and the pretarsus. Figure 1B shows a detail of these two last segments. The tarsus has five tarsomeres: a basitarsus, which is the largest tarsomere, and 4 smaller tarsomeres $\left(2 \mathrm{nd}-5^{\text {th }}\right)$. The distally situated pretarsus bears a pair of lateral bifid claws and an arolium, a small pad used to increase adhesion (Figures 1B,C) (Snodgrass, 1956; Goodman, 2003). Approximately 100 taste sensillae are located on the tarsus and pretarsus. These are mostly chaetic sensilla, which are evenly distributed between the five subsegments of the tarsus, and which are densely concentrated on the terminal claw-bearing pretarsus. Chaetic sensilla share similarities with those found on the mouth parts, with a mechanosensory cell ending at their base and four cells with dendrites running to the tip of the shaft (Whitehead and Larsen, 1976b).

Electrophysiological recordings were performed on chaetic sensillae, which could be easily identified by their external morphology and which were located on the third and fourth tarsomeres of the tarsus, and at the level of the claws of the pretarsus.

\section{Stimuli}

The tastants employed were $\mathrm{KCl}, \mathrm{NaCl}$, sucrose, quinine hydrochloride (henceforth quinine), salicin and amygdalin. All chemicals were obtained from Sigma-Aldrich (Saint-Quentin Fallavier, France). Depending on the experiment, chemicals were diluted in a solution of $\mathrm{KCl} 0.1$ or $0.01 \mathrm{mM}$, which was used as contact electrolyte. Solutions were kept at $-4^{\circ} \mathrm{C}$. To evaluate the effect of bitter compounds on sensillae responding to sucrose (De Brito Sanchez et al., 2005; Cocco and Glendinning, 2012; Kessler et al., 2012), we tested mixtures of $1 \mathrm{M}$ sucrose and either quinine $10 \mathrm{mM}$ or amygdalin $10 \mathrm{mM}$.

\section{Single sensillum recordings}

A glass electrode with an external diameter of $10-20 \mu \mathrm{m}$ was placed over a single taste sensillum. Electrodes were pulled from borosilicate glass capillaries. A chlorinated silver wire inserted into the contralateral eye was used as grounded reference electrode. The stimulating electrode was filled with the solution to be assayed (see above). The stimulation electrodes were stored in a humid chamber before use.

Stimuli were applied for $2 \mathrm{~s}$ with an interstimulus interval of $1 \mathrm{~min}$. In some experiments stimulation lasted $5 \mathrm{~s}$ in order to favor recording of cellular responses to bitter substances such as quinine, which in some insects (e.g., Heliothis virescens) exhibit a long latency (Jørgensen et al., 2007). The recording and reference electrodes were connected to a preamplifier (Taste Probe-SYNTECH, Kirchzarten, Germany). The electric signals were amplified $(\times 10)$ using a signal connection interface box (SYNTECH, Kirchzarten, Germany) in conjunction with a $100-3000 \mathrm{~Hz}$ bandpass filter. Experiments started when the recording electrode contacted the sensillum under study, which triggered data acquisition and storage on a hard disk (sampling rate $10 \mathrm{kHz}$ ). These data were then analyzed using Spike 2 and quantified by counting the number of spikes after stimulus onset. 
A

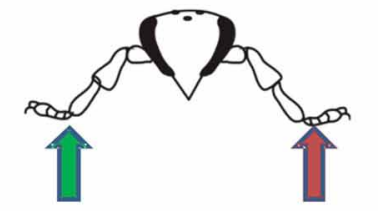

1) Bitter

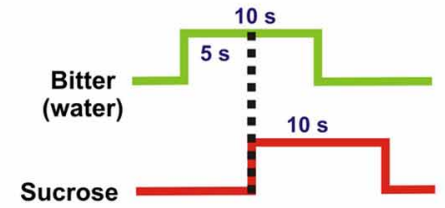

D

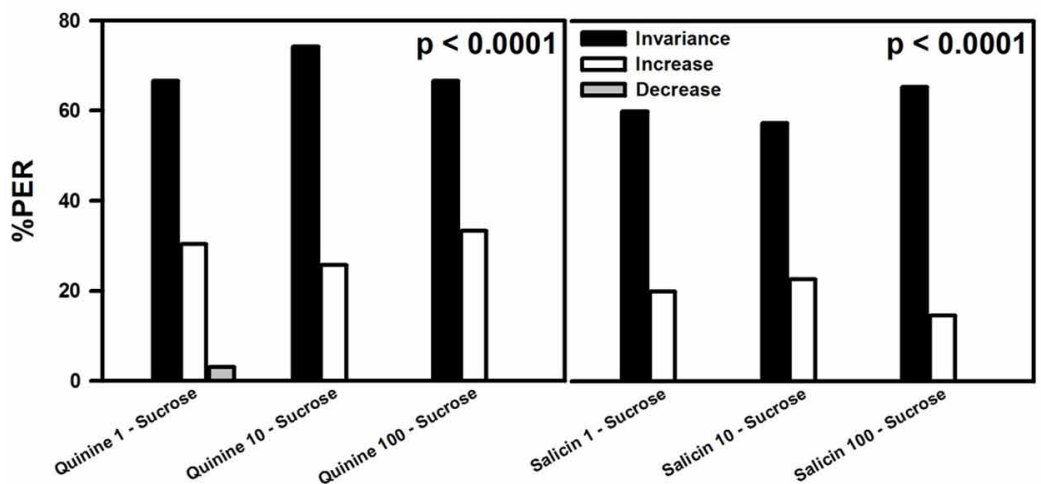

B

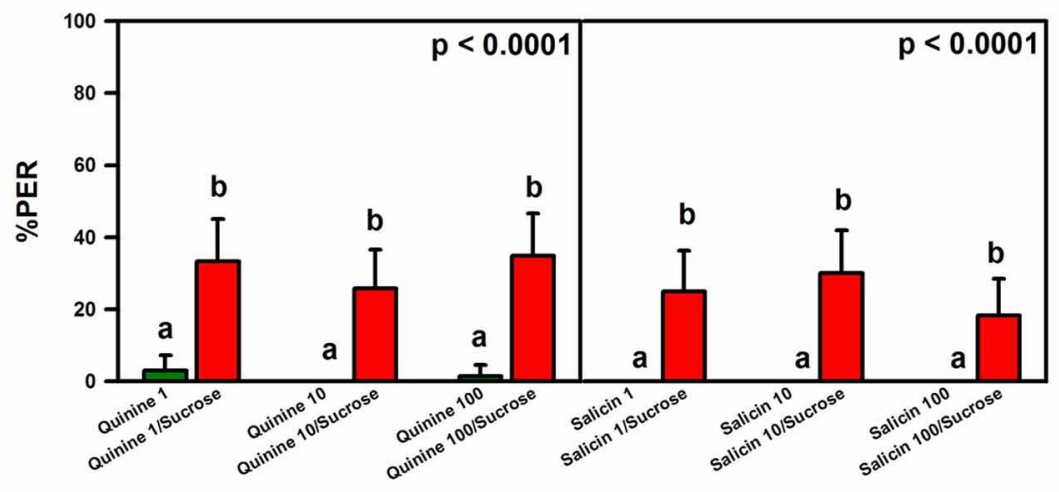

$\mathbf{F}$

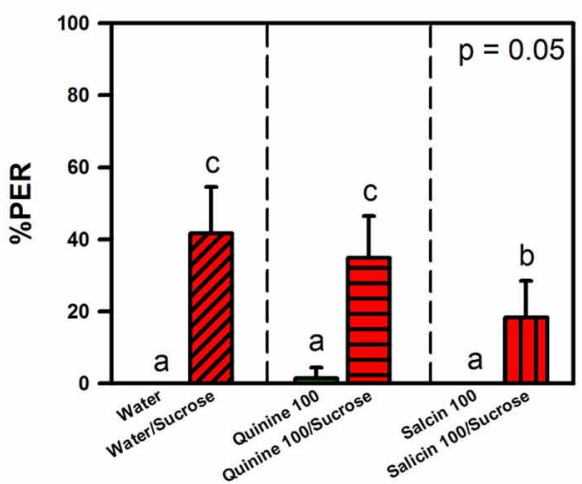

FIGURE 3 | Experiment 2. (A) Bees with amputated antennae were stimulated along three trials with quinine or salicin ("bitter", green arrow, green trace) of different concentrations on one fore-tarsus, and with sucrose solution $1 \mathrm{M}$ (red arrow; red trace) on the contralateral fore-tarsus to determine whether sucrose overcomes the potential inhibitory effect of the bitter substance and elicits PER. (B) \% PER upon stimulation with quinine (1, 10, and $100 \mathrm{mM}$; green bars) and sucrose $1 \mathrm{M}$ (red bars). (C) \% PER upon stimulation with salicin (1, 10, and $100 \mathrm{mM}$; green bars) and sucrose $1 \mathrm{M}$ (red bars). Different letters above bars indicate significant differences $(p<0.05)$.
(D) \% of bees into the invariance (black bars), increase (white bars), or decrease (gray bars) categories upon stimulation with sucrose $1 \mathrm{M}$ and quinine 1, 10, and $100 \mathrm{mM}$. (E) \% of bees into the invariance (black bars), increase (white bars), or decrease (gray bars) categories upon stimulation with sucrose $1 \mathrm{M}$ and salicin 1, 10, and $100 \mathrm{mM}$. (F) \% PER upon stimulation with water and sucrose $1 \mathrm{M}$ (diagonally hatched bar), quinine $100 \mathrm{mM}$ and sucrose $1 \mathrm{M}$ (horizontally hatched bar) and salicin $100 \mathrm{mM}$ and sucrose $1 \mathrm{M}$ (vertically hatched bar). Different letters above bars indicate significant differences $(p<0.05)$.

\section{RESULTS}

\section{BEHAVIORAL EXPERIMENTS}

Experiment 1: Induction of proboscis retraction by bitter substances We determined whether bitter substances applied on a foretarsus induce retraction of the proboscis once a proboscis extension reflex (PER) had occurred due to a prior stimulation with sucrose on the other fore-tarsus (Figure 2A). Quinine $(n=82)$, salicin $(n=77)$ and caffeine $(n=30)$ were used as potentially inhibitory substances. There were no significant differences between groups depending on the side (left or right fore-tarsus) of substance stimulation [ANOVA for repeated measurements; quinine: $F_{(1,80)}=0.23, p=0.64$; salicin: $F_{(1,75)}=0.11, p=$ 0.75 ; caffeine: $F_{(1,28)}=1.75, p=0.20$ ] so that data were pooled within each treatment.

Figures 2B-D shows the \% of PER during the $5 \mathrm{~s}$ of sucrose stimulation as reference (red bars), and during the $5 \mathrm{~s}$ overlap between sucrose and the bitter substance tested (green bars). In the case of quinine (Figure 2B), no retraction of proboscis was observed upon stimulation with all three concentrations tested. Response remained unchanged with respect to that elicited by sucrose solution $\left[F_{(5,405)}=0.83, p=0.53\right]$, thus showing that quinine did not exert an inhibitory effect on a prior response to sucrose solution. Responses to control stimulations with water and dry toothpick (not shown) remained constant and low along trials $\left[F_{(5,405)}=1.06, p=0.38\right]$ and were significantly lower than those to sucrose and quinine $\left[F_{(1,81)}=163.28\right.$, $p<0.0001]$. In the case of salicin, despite significant differences between trials $\left[F_{(5,380)}=3.88, p<0.002\right]$, responses to sucrose never decreased significantly within a trial due to salicin stimulation (Figure 2C). Responses to control stimulations with water and the dry toothpick (not shown) were homogeneous $\left[F_{(5,380)}=1.65, p=0.15\right]$ and significantly lower than those to sucrose and salicin $\left[F_{(1,76)}=203.20, p<0.0001\right]$. Finally, caffeine was also ineffective to induce proboscis retraction, irrespective of the concentration used [Figure 2D: $F_{(5,140)}=0.10, p=$ 0.99]. In this case, control stimulations with water and the dry 
toothpick induced heterogeneous responses $\left[F_{(5,140)}=3.84, p<\right.$ 0.003; not shown] but these were significantly lower than those induced by sucrose and caffeine $\left[F_{(1,28)}=54.19, p<0.0001\right]$. In all cases, the level of PER to sucrose was high, thus revealing a high appetitive motivation.

In order to refine the analyses on the basis of individual responses, we distinguished three main classes of responses occurring within a trial: "decrease" $(1 \rightarrow 0)$, in which sucrose induced PER and the bitter substance induced retraction, "increase" $(0 \rightarrow 1)$, in which sucrose did not induce PER but the bitter substance did, and "invariance", in which no response change was induced by the bitter substance with respect to sucrose solution $(0 \rightarrow 0$ and $1 \rightarrow 1)$. Upon stimulation with sucrose and quinine (Figure 2E), most of the bees (78\% in average) fell into the invariance category (black bars), thus confirming that irrespective of the concentration of quinine used these bees did not change their response upon tarsal quinine contact. Only $11 \%$ of bees in average fell into the increase (white bars) or the decrease category (gray bars). Differences between categories were significant within each trial ( $\chi^{2}$ test, $p<0.01$ in all cases). A similar conclusion was reached in the case of bees stimulated with sucrose and salicin (Figure 2F). Eighty-one percent of the bees fell into the invariance category, $4 \%$ into the increase category and $14 \%$ into the decrease category. Differences between categories were significant within each trial ( $\chi^{2}$ test, $p<0.01$ in all cases). In the case of stimulation with sucrose and caffeine (Figure 2G), 86\% of the bees fell into the invariance category, $9 \%$ into the increase category and $6 \%$ into the decrease category. Differences between categories were significant within each trial ( $\chi^{2}$ test, $p<0.01$ in all cases). Thus, for all three substances, the low percentages corresponding to the decrease category showed that the bitter substances tested did not induce significant proboscis retraction after sucrose stimulation.

\section{Experiment 2: Inhibition of appetitive proboscis extension by bitter substances}

We analyzed whether stimulation with sucrose solution on a fore-tarsus overcomes a potential inhibitory effect of stimulation with a bitter-substance on the other fore-tarsus and thus triggers PER. Quinine $(n=66)$ and salicin $(n=60)$ were used as potentially inhibitory substances. There were no significant differences between groups depending on the side (left or right fore-tarsus) of substance stimulation [ANOVA for repeated measurements; quinine: $F_{(1,64)}=0.11, p=0.74$; salicin: $\left.F_{(1,58)}=0.37, p=0.54\right]$ so that data were pooled within each treatment.

Figures 3B,C shows the \% of PER during the $5 \mathrm{~s}$ of bitter stimulation as reference (green bars), and during the $5 \mathrm{~s}$ overlap between sucrose and the bitter substance tested (red bars). Figure 3B shows that bees did not extend the proboscis upon quinine contact with one fore tarsus, irrespective of the concentration used. Simultaneous stimulation with quinine and sucrose solution on opposite fore tarsi induced a significant level of PER thus showing that quinine did not inhibit $\operatorname{PER}\left[F_{(5,325)}=18.73, p<0.00001\right]$. Responses to quinine were all equivalent (Tukey post hoc tests; NS for all comparisons) and significantly different from those to sucrose solution (Tukey post hoc tests; $p<0.001$ for all comparisons), which were also equivalent between trials (Tukey post hoc tests; NS for all comparisons). Responses to control stimulations with water and the dry toothpick (not shown) remained constant and low along trials $\left[F_{(5,325)}=1.68, p=0.14\right]$. Figure 3C shows a similar pattern of responses upon stimulation with salicin and sucrose: bees did not extend the proboscis upon salicin contact with one fore tarsus, irrespective of the concentration of salicin solution used, while they extended the proboscis upon simultaneous stimulation with sucrose solution on the opposite fore tarsus $\left[F_{(5,295)}=13.03, p<0.00001\right]$. Responses to salicin were all equivalent (Tukey post hoc tests; NS for all comparisons) and significantly different from those to sucrose solution (Tukey post hoc tests; $p<0.001$ for all comparisons), which were also equivalent between trials (Tukey post hoc tests; NS for all comparisons). Responses to control stimulations (not shown) remained constant and low along trials $\left[F_{(5,925)}=1.68, p=0.14\right]$.

An analysis of individual responses in terms of the three classes of response variations, "decrease" $(1 \rightarrow 0)$, "increase" $(0 \rightarrow 1)$ and "invariance" $(0 \rightarrow 0$ and $1 \rightarrow 1)$, showed that upon stimulation with quinine and sucrose (Figure 3D), 69\% of the bees in average fell into the invariance category, 30\% into the increase category and $1 \%$ into the decrease category. Differences between the three categories were significant within each trial ( $\chi^{2}$ test, $p<0.01$ in all cases). Stimulation with salicin resulted in $76 \%$ of bees in average in the invariance category and $24 \%$ in the increase category. No bee fell into the decrease category (Figure 3E). Differences between the three categories were significant within each trial ( $\chi^{2}$ test, $p<0.01$ in all cases).

These results might suggest that quinine and salicin are aversive and inhibit PER elicited by concomitant stimulation with sucrose because the average \% of PER recorded was low (30\% upon quinine and sucrose stimulation, and $24 \%$ upon salicin and sucrose stimulation). Yet, the low percentages of responsiveness to sucrose could be due to antennal amputation rather than reflecting an aversive nature of quinine and salicin. Antennal amputation has been shown to decrease sucrose responsiveness upon tarsal stimulation (De Brito Sanchez et al., 2008) so that the previous experiment was repeated with intact bees (Figure 4A).

Quinine $(n=93)$ and salicin $(n=56)$ were again used as potentially inhibitory substances. There were no significant differences between groups depending on the side (left or right fore-tarsus) of substance stimulation [ANOVA for repeated measurements; quinine: $F_{(1,91)}=1.53, p=0.22$; salicin: $F_{(1,54)}=$ $0.43, p=0.51]$ so that data were pooled within each treatment.

The pattern of responses of intact bees upon stimulation with quinine and sucrose (Figure 4B) was similar to that exhibited by bees which had their antennae cut (Figure 3B). Bees did not extend their proboscis upon quinine contact with one fore tarsus, irrespective of the concentration of quinine solution used, while they extended their proboscis upon simultaneous stimulation with quinine and sucrose solution on opposite fore tarsi $\left[F_{(5,460)}=23.12, p<0.00001\right]$. Responses to quinine were all equivalent (Tukey post hoc tests; NS for all comparisons) and significantly different from those to sucrose solution (Tukey post hoc tests; $p<0.001$ for all comparisons), which were also equivalent between trials (Tukey post hoc tests; NS for all comparisons). Similarly to the experiment with amputated bees, the average \% of PER to sucrose upon simultaneous stimulation with quinine and sucrose solution was $28 \%$. 
A

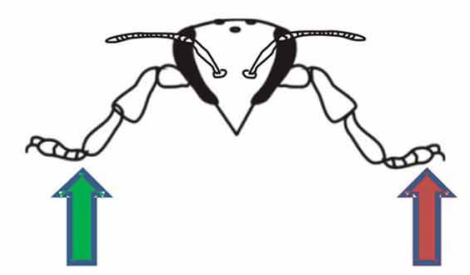

1) Bitter

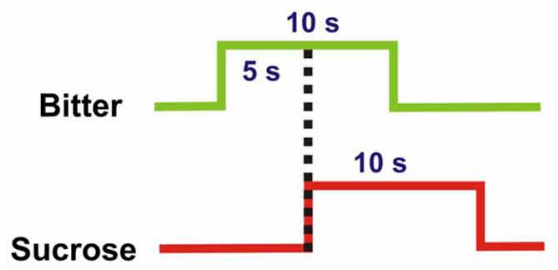

B

C

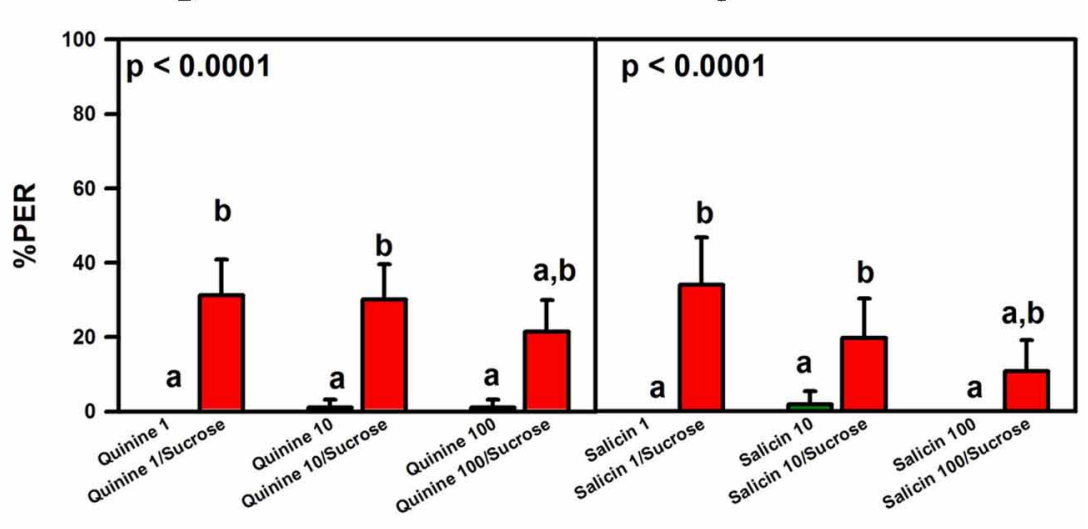

D

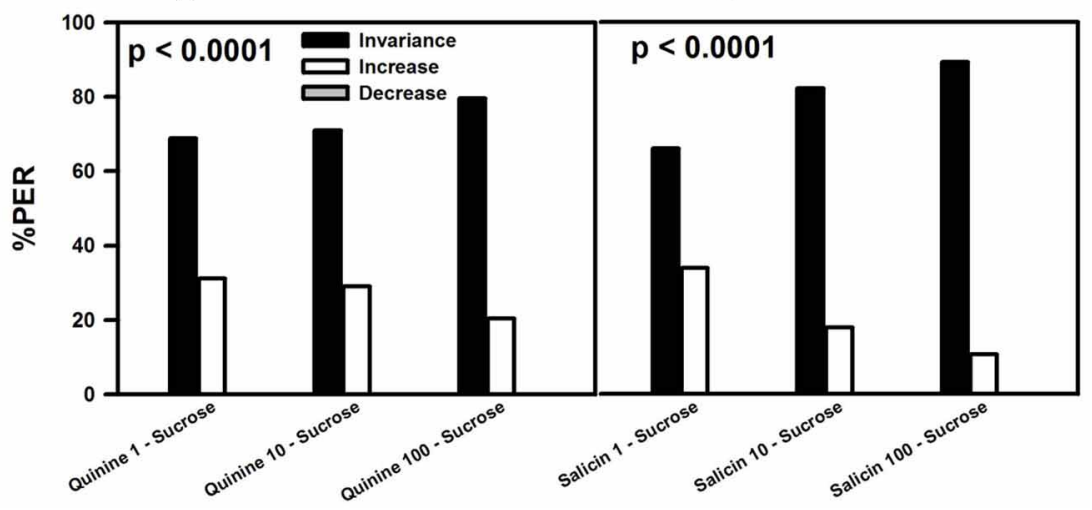

FIGURE 4 | Experiment 2. (A) Bees with intact antennae were stimulated along three trials with quinine or salicin ("bitter," green arrow, green trace) of different concentrations on one fore-tarsus, and with sucrose solution $1 \mathrm{M}$ (red arrow; red trace) on the contralateral fore-tarsus to determine whether sucrose overcomes the potential inhibitory effect of the bitter substance and elicits PER. (B) \% PER upon stimulation with quinine (1, 10, and $100 \mathrm{mM}$; green bars) and sucrose $1 \mathrm{M}$ (red bars). (C) \% PER upon stimulation with salicin (1, 10, and $100 \mathrm{mM}$; green bars) and sucrose $1 \mathrm{M}$ (red bars). Different letters above bars indicate significant differences $(p<0.05)$. (D) \% of bees into the invariance (black bars), increase (white bars), or decrease (gray bars) categories upon stimulation with sucrose $1 \mathrm{M}$ and quinine 1, 10, and $100 \mathrm{mM}$. (E) \% of bees into the invariance (black bars), increase (white bars), or decrease (gray bars) categories upon stimulation with sucrose $1 \mathrm{M}$ and salicin 1,10 , and $100 \mathrm{mM}$.
Similarly to antenna-amputated bees (Figure 3C), intact bees did not extend their proboscis upon contact of one fore tarsus with salicin solution (Figure 4C), irrespective of the concentration used, while they extended their proboscis upon simultaneous stimulation with salicin and sucrose solution on opposite fore tarsi $\left[F_{(5,275)}=12.62, p<0.00001\right]$. As in the experiment with antenna-amputated bees, the average \% of PER to sucrose upon simultaneous stimulation with salicin and sucrose solution was $21 \%$.

The analysis of individual responses of intact bees in terms of the increase, decrease, and invariance categories yielded the same results as those obtained in antenna-amputated bees stimulated with quinine (Figure 4D) or salicin (Figure 4E). Stimulation with quinine resulted in $73 \%$ of bees in average in the invariance category, $27 \%$ in the increase category and $0 \%$ in the decrease category. Stimulation with salicin determined that $79 \%$ of the bees fell into the invariance category, $21 \%$ into the increase category and $0 \%$ into the decrease category.

Thus, the low percentages of responsiveness to sucrose were not due to antennal amputation as the same percentages were obtained in experiments in which bees conserved their antennae. To determine whether the two bitter substances did indeed exert a partial inhibitory effect on PER upon sucrose stimulation due to their aversive nature, we performed a final control experiment with antenna-amputated bees in which we replaced the first stimulation with a bitter substance by stimulation with water on one fore tarsus, followed by stimulation with sucrose solution on the opposite fore tarsus (Figure 3F).

No significant differences were found between the subgroup that received water on the left fore tarsus (and sucrose on the right fore tarsus) and that receiving water on the right fore tarsus (and sucrose on the left fore tarsus) $\left[F_{(1,58)}=0.55, p=0.46\right]$ so that results of both subgroups were pooled (Figure $3 \mathbf{F}$ ). The responses of two other groups run in parallel and stimulated with quinine $100 \mathrm{mM}$ and sucrose, and with salicin $100 \mathrm{mM}$ and sucrose, are also shown.

Bees did not show PER to water alone upon contact with one fore-tarsus, while they showed it when sucrose contacted the other fore tarsus. The \% of PER upon simultaneous stimulation with water and sucrose on opposite fore tarsi was, however, only 
$40 \%$ so that responses of the water group did not differ significantly from those of the quinine and the salicin groups even if the lack of significance was marginal $\left[F_{(2,183)}=3.01, p=0.05\right]$. Post hoc analyses showed that responses to water, quinine and salicin alone did not differ significantly (Tukey tests; all comparisons NS) while responses to simultaneous stimulation with water and sucrose, and quinine and sucrose were significantly higher than responses to water, quinine and salicin alone (Tukey tests; all comparisons $p<0.05$ ). Responses to simultaneous stimulation with salicin and sucrose reached an intermediate level. Thus, simultaneous stimulation with water and sucrose induced the same effect on PER as simultaneous stimulation with quinine and sucrose. The analysis of individual responses (not shown) yielded $60 \%$ of bees in the invariance category, $40 \%$ in the increase category and $0 \%$ in the decrease category.

The lower levels of PER registered in all experiments (Figures 3 and 4) seem, therefore, due to contradictory gustatory input from both fore tarsi and not to a potential aversive nature of bitter substances. The fact that water yielded the same pattern of responses as concentrated quinine solution confirms that sensitivity for bitter substances is rather limited at the tarsal level. Only the fact that concentrated salicin solution induced a lower level of PER upon sucrose stimulation compared to quinine solution and water (Figure 3F) indicates some inhibitory effect of salicin.

\section{ELECTROPHYSIOLOGICAL EXPERIMENTS}

Experiment 3: Responses of tarsomere sensilla to sweet, bitter and salty substances

We recorded responses of gustatory receptor neurons located in chaetic sensilla of the third and fourth tarsomeres of the foreleg, upon 2-s stimulation with sucrose $1 \mathrm{M}$, quinine solution 1 and $10 \mathrm{mM}$, salicin $1 \mathrm{mM}, \mathrm{KCl} 0.1 \mathrm{mM}$ and $\mathrm{NaCl} 100 \mathrm{mM}$. The contact electrolyte used for all solutions was $\mathrm{KCl} 0.1 \mathrm{mM}$ which proved to be effective and did not elicit significant spiking activity per se in recordings of chaetic sensilla performed at the level of the antenna (De Brito Sanchez et al., 2005). Left and right fore legs were used indistinctly. Figure $\mathbf{5 A}$ shows examples of recordings obtained. Contrary to our expectations, the contact electrolyte $(0.1 \mathrm{mM} \mathrm{KCl})$ elicited significant spiking activity (Figure 5A) even if higher concentrations of $\mathrm{KCl}$ (e.g., $10 \mathrm{mM}$ ) have been used as contact electrolyte to study gustatory responses in other appendages such as the antennae of bees and moths without inducing significant neural activity (De Brito Sanchez et al., 2005; Jørgensen et al., 2007). As shown by Figure 5A, recordings obtained upon stimulation with different tastants such as $\mathrm{KCl}$ and quinine showed a striking similarity and rendered difficult distinguishing between different receptor neurons based on the amplitude of action potentials.

Figure 6A shows mean responses $( \pm S E)$ to the different tastants, normalized to the response obtained for the contact electrolyte alone $(\mathrm{KCl} 0.1 \mathrm{mM})$. This normalization is necessary because levels of response may differ considerably between individuals. Data were obtained from 6 bees in which responses for the six tastants assayed were recorded 4 times $(n=144)$ in 7 different sensilla. Normalized responses varied significantly depending on the tastant assayed [Figure 6A; ANOVA for repeated measurements: $\left.F_{(5,115)}=9.02, p<0.0001\right]$. Post hoc analyses (Tukey test) showed that responses to sucrose solution $1 \mathrm{M}$ were significantly lower than those to $\mathrm{NaCl} 100 \mathrm{mM}$, quinine $10 \mathrm{mM}$ and salicin $1 \mathrm{mM}$ (Tukey tests: $p<0.05$ for all three comparisons). Responses to the three bitter solutions (quinine 1
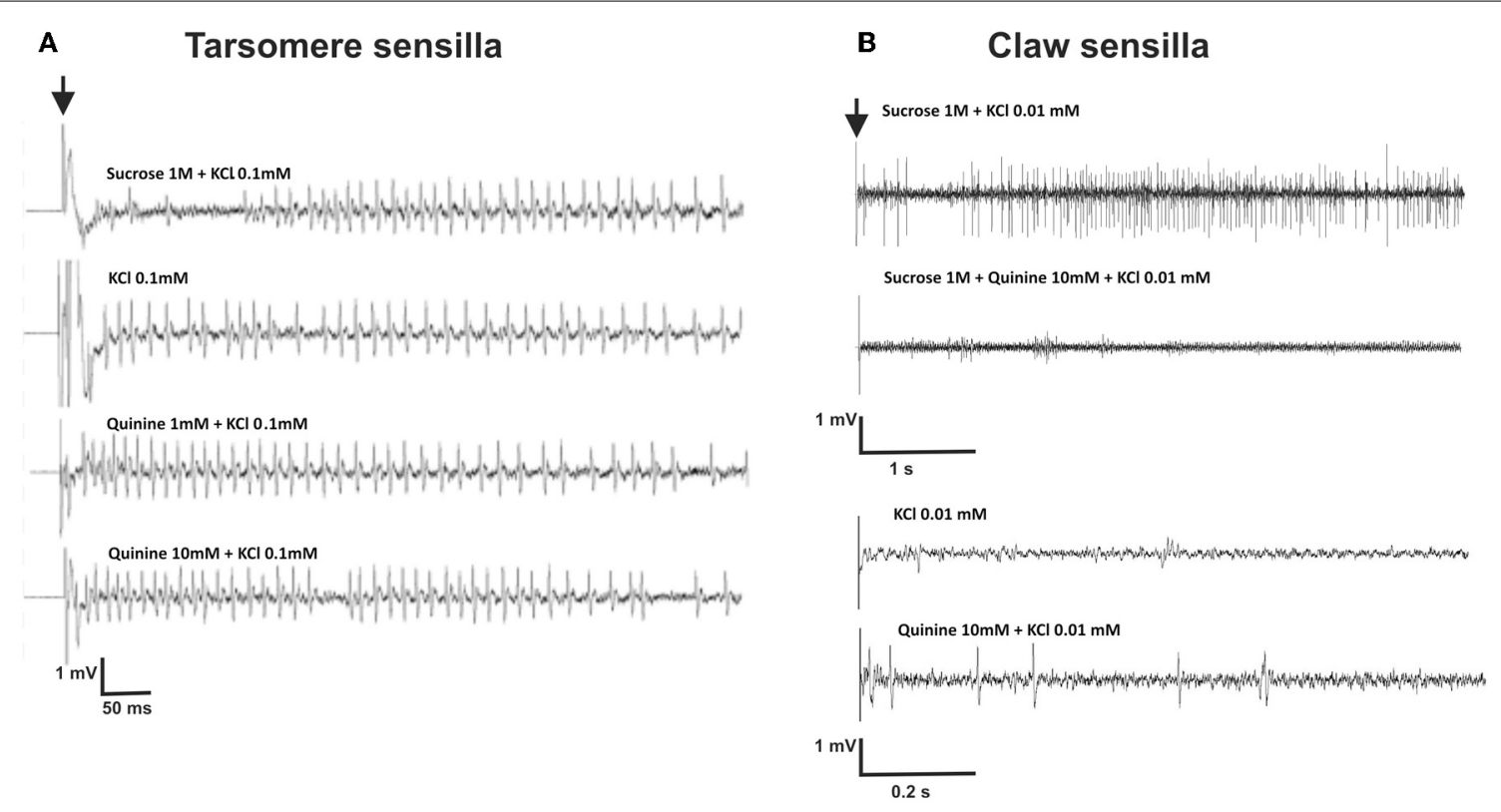

FIGURE 5 | (A) Experiment 3: Examples of extracellular recordings performed at the level of chaetic sensilla located on the third and fourth tarsomeres of the foreleg, upon 2-s gustatory stimulation. The contact electrolyte used for all solutions was $\mathrm{KCl} 0.1 \mathrm{mM}$. The black

arrow indicates the start of stimulation. Vertical scale: $1 \mathrm{mV}$; horizontal scale: $50 \mathrm{~ms}$. (B) Experiment 6: Examples of extracellular recordings performed at the level of chaetic sensilla located on the claws, upon 5-s gustatory stimulation. 


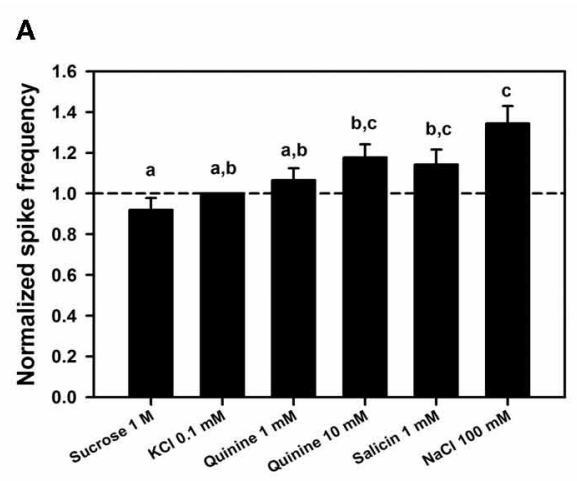

FIGURE 6 | (A) Mean normalized spike frequencies ( \pm SE) obtained upon stimulation with the different tastants assayed. Responses (action potentials per second) were normalized to those recorded for $\mathrm{KCl} 0.1 \mathrm{mM}$ (hatched horizontal line). Data were obtained from 6 bees in which responses for the six tastants assayed were recorded 4 times $(n=144)$ in 7

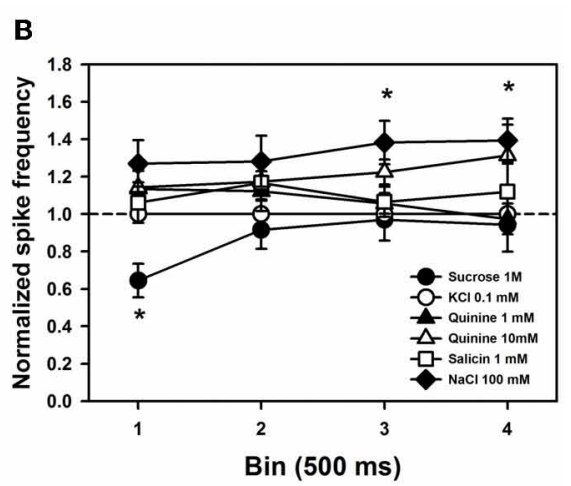

different sensilla. Different letters above bars indicate significant differences $(p<0.05)$. (B) Temporal analysis of mean normalized spike frequencies along four consecutive bins of $500 \mathrm{~ms}$ each, starting at the onset and finishing at the offset of stimulation. Asterisks indicate significant differences between tastants within a bin $(p<0.05)$. and $10 \mathrm{mM}$ and salicin $1 \mathrm{mM}$ ) did not differ (Tukey test: $p>0.05$ for all three comparisons) and were also indistinguishable from responses to the contact electrolyte $\mathrm{KCl} 0.1 \mathrm{mM}$ that was also present in these bitter solutions ( $p>0.05$ for all three comparisons). These results suggest, therefore, both a lower sensitivity for sucrose and a higher sensitivity for $\mathrm{NaCl}$ and that responses to quinine and salicin could be, in fact, responses to the $\mathrm{KCl}$ present in these solutions.

To determine whether responses to tastants could be distinguished from those to $\mathrm{KCl}$ in terms of their temporal course, we analyzed normalized responses along four consecutive bins of $500 \mathrm{~ms}$ each, starting at the onset and finishing at the offset of stimulation (Figure 6B). No significant differences between bins were detected $\left[F_{(3,18)}=0.60, p=0.63\right]$ but differences between tastants existed $\left[F_{(5,30)}=6.82, p<0.0005\right]$. These differences were due to responses to sucrose, which were significantly lower than responses to the three bitter substances and $\mathrm{NaCl}$ in the 1st bin ( $p<0.005$ for all four comparisons). No significant differences were found within the 2 nd bin, while in the 3rd and 4th bins, responses to $\mathrm{NaCl} 100 \mathrm{mM}$ were significantly higher than those to sucrose $1 \mathrm{M}$ and than those to sucrose $1 \mathrm{M}, \mathrm{KCl} 0.1 \mathrm{mM}$ and quinine $1 \mathrm{mM}$, respectively. Responses to $\mathrm{NaCl} 100 \mathrm{mM}$ remained high along bins, and except for the 2nd bin, were significantly higher than those to sucrose $1 \mathrm{M}$. No significant differences between responses to $\mathrm{KCl}$ and to bitter substances were found along the four bins $(p>0.05$ for all comparisons), thus showing that temporal dynamics does not allow concluding on the existence of tarsomere cells tuned to bitter substances. Neither the form of action potentials, nor their size or frequency allowed separating responses to $\mathrm{KCl}$ from responses to the bitter tastants quinine and salicin. A similar conclusion may apply to sucrose detection: except for the first bin, spike activity upon sucrose stimulation did not differ from that elicited by $\mathrm{KCl} 0.1 \mathrm{mM}$, thus suggesting that the low activity recorded upon sucrose stimulation was due to the contact electrolyte.

\section{Experiment 4: Dose-response curve of tarsomere sensilla for KCL}

The previous results suggest that responses to sucrose and to bitter substances of gustatory receptor neurons located in chaetic sensilla of the third and fourth tarsomeres of the foreleg were due to a receptor cell responding to $\mathrm{KCl}$ at very low concentrations.

To determine whether a KCl-receptor cell existed within the sensilla studied, we performed an experiment aimed at establishing a dose-response curve to $\mathrm{KCl}$. We quantified responses to 2-s stimulations with five increasing concentrations of $\mathrm{KCl}$ : $0.01,0.1$, 1,10 , and $100 \mathrm{mM}$. Responses were standardized to responses to $\mathrm{KCl} 100 \mathrm{mM}$ which induced in all cases maximal responsiveness. Figure 7A shows the responses of 6 different sensilla of 6 bees to the five $\mathrm{KCl}$ concentrations, each one being tested 4 times $(n=120)$.

Responses increased significantly with $\mathrm{KCl}$ concentration $\left[F_{(4,92)}=16.10, p<0.0001\right]$; specifically, responses to the two lower $\mathrm{KCl}$ concentrations $(0.01$ and $0.1 \mathrm{mM})$ were significantly lower than those elicited by the three higher concentrations $(1,10$, and $100 \mathrm{mM}, p<0.005$ for all six comparisons; Figure 7A). This variation, which is incompatible with the response of a water receptor cell, shows that the discharge rate observed for the concentration of $0.1 \mathrm{mM} \mathrm{KCl}$ used as contact electrolyte in the previous experiment was due to the existence of at least one $\mathrm{KCl}$ cell. It also suggests that responses to both bitter substances and sucrose were in fact due to the presence of this electrolyte in the solutions rather than to these substances themselves. The next experiment analyzed this possibility.

\section{Experiment 5: Dose-response curve of tarsomere sensilla for quinine and sucrose}

To determine whether tarsomere sensilla host specific gustatory receptor neurons tuned to bitter substances and sucrose, we aimed at establishing dose-response curves for quinine, on the one hand, and for sucrose on the other hand.

To establish a dose-response curve for quinine, we varied quinine concentration but kept constant the concentration of the 


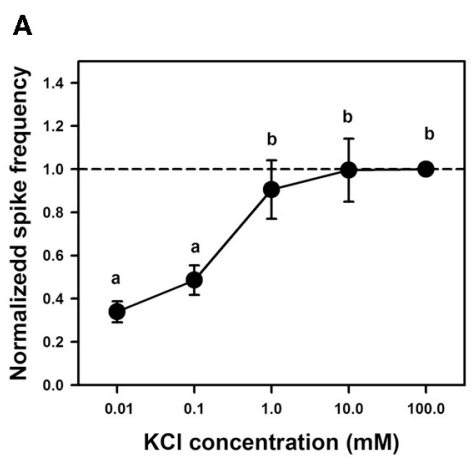

B

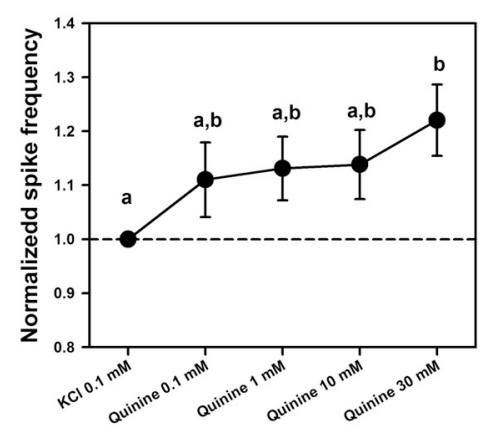

C

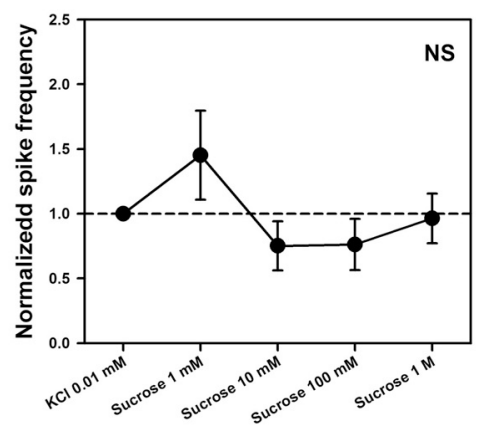

FIGURE 7 | (A) Experiment 4. Mean normalized spike frequencies ( \pm SE) obtained upon stimulation with 5 different concentrations of $\mathrm{KCl}$ solution: $0.01,0.1,1,10$, and $100 \mathrm{mM}$. Responses (action potentials per second) were normalized to those recorded for $\mathrm{KCl} 100 \mathrm{mM}$ (hatched horizontal line), which yielded maximal responsiveness. Data were obtained from 6 bees in which responses to the $5 \mathrm{KCl}$ concentrations were recorded 4 times in 6 different sensilla $(n=120)$. Different letters above bars indicate significant differences $(p<0.05)$. (B) Experiment 5 . Mean normalized spike frequencies $( \pm S E$ ) obtained upon stimulation with $\mathrm{KCl} 0.1 \mathrm{mM}$ and 4 different concentrations of quinine solution including $\mathrm{KCl} 0.1 \mathrm{mM}$ as contact electrolyte: $0.1,1,10$, and $30 \mathrm{mM}$. Responses (action potentials per second) were normalized to those recorded for $\mathrm{KCl} 0.1 \mathrm{mM}$ (hatched horizontal line). Data were obtained from 8 bees in which responses to the 5 substances assayed were recorded 4 times in 9 different sensilla $(n=180)$. Different letters above bars indicate significant differences $(p<0.05)$. (C) Experiment 5: Mean normalized spike frequencies $( \pm S E$ ) obtained upon stimulation with $\mathrm{KCl}$ $0.01 \mathrm{mM}$ and 4 different concentrations of sucrose solution-1 $\mathrm{mM}$, $10 \mathrm{mM}, 100 \mathrm{mM}$ and $1 \mathrm{M}$-including $\mathrm{KCl} 0.01 \mathrm{mM}$ as contact electrolyte. Responses (action potentials per second) were normalized to those recorded for $\mathrm{KCl} 0.01 \mathrm{mM}$ (hatched horizontal line). Stimulations lasted $1 \mathrm{~s}$. The graph shows the responses of 14 different sensilla of 5 bees to the 5 substances assayed, each one being tested once $(n=70)$. No differences between stimuli were found; NS, non-significant. contact electrolyte $(\mathrm{KCl} 0.1 \mathrm{mM})$ in order to determine whether responses increased progressively, consistently with the presence of a bitter receptor within the sensilla studied, or remained constant if they were due to the $\mathrm{KCl}$ cell. We recorded responses to $\mathrm{KCl} 0.1 \mathrm{mM}$ and to solutions of quinine $0.1,1,10$, and $30 \mathrm{mM}$, all containing $\mathrm{KCl} 0.1 \mathrm{mM}$. Stimulations lasted $5 \mathrm{~s}$ due to the potential long latency of a putative "quinine cell" (Jørgensen et al., 2007). Preliminary experiments showed that the highest concentration of quinine $(30 \mathrm{mM})$ was at the limit of cell tolerance as it could induce higher discharge rates followed by cell death in some cases. Figure 7B shows the responses (spikes/seconds, normalized to $\mathrm{KCl}$ responses) of 9 different sensilla of 8 bees to the 5 substances assayed, each one being tested 4 times $(n=180)$.

Responses normalized to those induced by the contact electrolyte increased significantly with quinine concentration [Figure 7B: $\left.F_{(4,140)}=3.98, p<0.005\right]$. Yet post hoc analyses indicated that significance was introduced by the comparison between the highest concentration of quinine assayed $(30 \mathrm{mM})$ and $\mathrm{KCl} 0.1 \mathrm{mM}$ alone (Tukey test: $p<0.001$ ). All other comparisons were non-significant. When the analysis was circumscribed to all four quinine concentrations $(0.1-30 \mathrm{mM})$, no significant differences were detected $\left[F_{(3,105)}=1.92, p=0.13\right]$. The increase in responses found for quinine $30 \mathrm{mM}$ with respect to $\mathrm{KCl}$ alone could be due to enhanced responsiveness following cell damage by excessive quinine concentration. The fact that no significant variation existed between all quinine concentrations over two orders of magnitude shows that responses to quinine solutions were in fact due to the presence of gustatory receptor cells responding to the contact electrolyte $\mathrm{KCl} 0.1 \mathrm{mM}$, which was common to the bitter tastants assayed.
To establish a dose-response curve for sucrose, we diminished the concentration of the contact electrolyte to $0.01 \mathrm{mM}$ to avoid interferences from the salt in the sucrose responses and to better visualize these responses. We varied sucrose concentration but kept constant the concentration of $\mathrm{KCl}$ in order to determine whether responses increased progressively because of the presence of a sucrose receptor cell, or remained constant because they were due to the $\mathrm{KCl}$ cell. We recorded responses to $\mathrm{KCl} 0.01 \mathrm{mM}$ and to solutions of sucrose $1,10,100$, and $1 \mathrm{M}$, all containing $\mathrm{KCl}$ $0.01 \mathrm{mM}$. Stimulations lasted $1 \mathrm{~s}$. Figure 7C shows the responses (spikes/seconds, normalized to $\mathrm{KCl}$ responses) of 14 different sensilla of 5 bees to the 5 substances assayed, each one being tested once $(n=70)$.

Responses normalized to those induced by the contact electrolyte did not vary significantly with sucrose concentration over four orders of magnitude (Figure 7C). When the analysis was circumscribed to all four sucrose concentrations ( $1 \mathrm{mM}-1 \mathrm{M})$, no significant differences were detected $\left[F_{(3,39)}=2.46, p=0.08\right]$ despite the apparent increase of responses to sucrose $1 \mathrm{mM}$. This result indicates that activity elicited by sucrose solution was in fact due to the presence of gustatory receptor cells responding to the contact electrolyte $\mathrm{KCl} 0.01 \mathrm{mM}$.

\section{Experiment 6: Responses of claw sensilla to sucrose, bitter substances and mixtures of sucrose and bitter substances}

We finally aimed at determining the sensitivity of chaetic sensilla located on the claws to perform a comparative analysis with those recorded on the tarsomeres. We used $\mathrm{KCl} 0.01 \mathrm{mM}$ as contact electrolyte and tested the effect of $\mathrm{KCl}$, sucrose, quinine, amygdalin, and mixtures of sucrose and quinine, and of sucrose 
and amygdalin. Responses were normalized to response levels obtained for the contact electrolyte.

Figure 5B shows examples of recordings obtained for claw sensilla. Contrary to recordings obtained for tarsomere sensilla (Figure 5A), responses to sucrose $1 \mathrm{M}$ were clearly different from those obtained for the contact electrolyte $\mathrm{KCl} 0.01 \mathrm{mM}$. Figures 8A,B shows mean responses $( \pm S E)$ of claw sensilla and of tarsomere sensilla to the different tastants, normalized to the response obtained for the contact electrolyte $(\mathrm{KCl} 0.01 \mathrm{mM})$. In order to facilitate comparisons between claw and tarsomere sensilla, recordings of tarsomere sensilla were performed again, using $\mathrm{KCl} 0.01 \mathrm{mM}$ as contact electrolyte (in our previous characterization of these sensilla $\mathrm{KCl} 0.1 \mathrm{mM}$ was used). For both kinds of sensilla, stimulations lasted $5 \mathrm{~s}$.

Figure 8A shows the normalized spike frequencies of 12 tarsomere sensilla of 5 bees in response to the 6 stimuli assayed, each one being tested once $(n=72)$. Responses to the different stimuli did not vary significantly $\left[F_{(5,55)}=2.32, p=0.06\right]$. As in Experiment 3, responses to sucrose $1 \mathrm{M}$ were similar to those induced by $\mathrm{KCl}(p=0.59$; see also Figure 6A) even if the contact electrolyte was now diluted in one order of magnitude. Furthermore, responses induced by the bitter substances quinine $10 \mathrm{mM}$ and amygdalin $10 \mathrm{mM}$ did also not differ from those recorded to the electrolyte alone and to sucrose $1 \mathrm{M}(p=0.90$ and 0.67 , respectively). Both mixtures of quinine and sucrose and amygdalin and sucrose did not induce any change in responses with respect to the bitter substance or the sucrose alone $(p>0.05$ for all comparisons).

In the case of claw sensilla, a different pattern of responses was obtained. Figure 8B shows the normalized spike frequencies of 13 claw sensilla of 4 bees in response to the 6 stimuli assayed, each one being tested once $(n=78)$. Normalized spike frequencies varied significantly with the stimulus assayed $\left[F_{(5,60)}=5.11\right.$, $p<0.001]$. While responses to the bitter substances quinine $10 \mathrm{mM}$ and amygdalin $10 \mathrm{mM}$ did not differ from those to the contact electrolyte $\mathrm{KCl} 0.01 \mathrm{mM}$ ( $p=1$ for both comparisons), responses to sucrose solution $1 \mathrm{M}$ were significantly higher than those induced by these three tastants ( $p<0.01$ for all 3 comparisons), thus suggesting that a sensitive sucrose receptor cell exists within chaetic sensilla of the claws. This receptor was inhibited by quinine $10 \mathrm{mM}$ as shown by the fact that responses to sucrose $1 \mathrm{M}$ and to the mixture of sucrose $1 \mathrm{M}$ and quinine $10 \mathrm{mM}$ differed significantly $(p<0.01)$. In fact, the addition of quinine to the sucrose solution lowered the response to the same level as that of the contact electrolyte $\mathrm{KCl} 0.01 \mathrm{mM}(p=1)$. The other bitter substance, amygdalin $10 \mathrm{mM}$, did not induce inhibition of the sucrose receptor; responses to sucrose $1 \mathrm{M}$ and to the mixture of sucrose $1 \mathrm{M}$ and amygdalin $10 \mathrm{mM}$ did not differ significantly $(p=0.83)$.

The differences between tarsomere and claw sensilla can also be visualized by comparing the temporal course of their responses to the tastants assayed. To this end, we analyzed normalized responses along the $5 \mathrm{~s}$ of stimulation (from stimulus onset to offset) (Figure 9). In the case of tarsomere sensilla (Figure 9A), neither the factor "substance" $\left[F_{(3,44)}=1.88, p=0.15\right]$ nor the interaction "substance $\times$ second" was significant $\left[F_{(12,176)}=\right.$ $0.88, p=0.56]$, thus showing that for all substances assayed the temporal pattern of responses was similar. There were significant differences between seconds of stimulation [factor "second": $\left.F_{(4,176)}=5.35, p<0.0005\right]$ but within each second, the responses obtained for the different tastants were statistically similar. This result confirms the prior temporal analysis performed

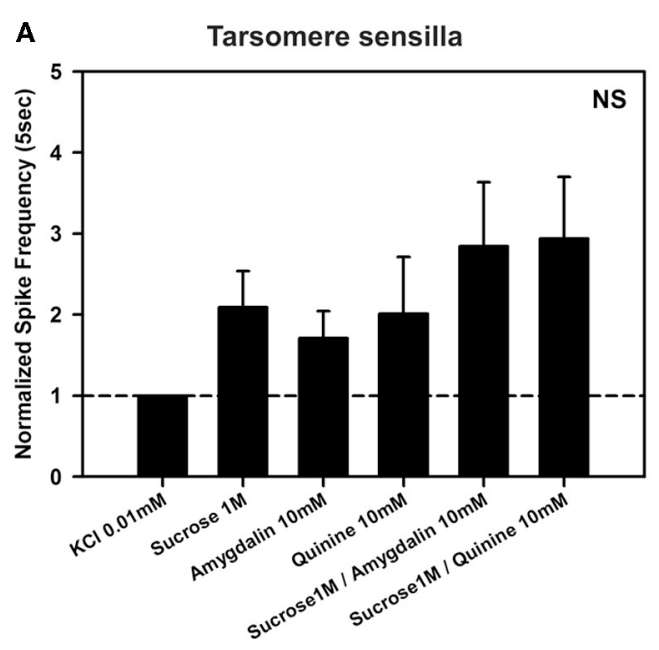

FIGURE 8 | Experiment 6. (A) Chaetic sensilla of the 3rd and 4th tarsomeres. Mean normalized spike frequencies $( \pm S E$ ) obtained upon stimulation with the different tastants assayed. Responses (action potentials per second) were normalized to those recorded for $\mathrm{KCl}$ $0.01 \mathrm{mM}$ (hatched horizontal line). Data were obtained from 12 tarsomere sensilla of 5 bees in response to the 6 stimuli assayed, each one being tested once $(n=72)$. NS, non significant.

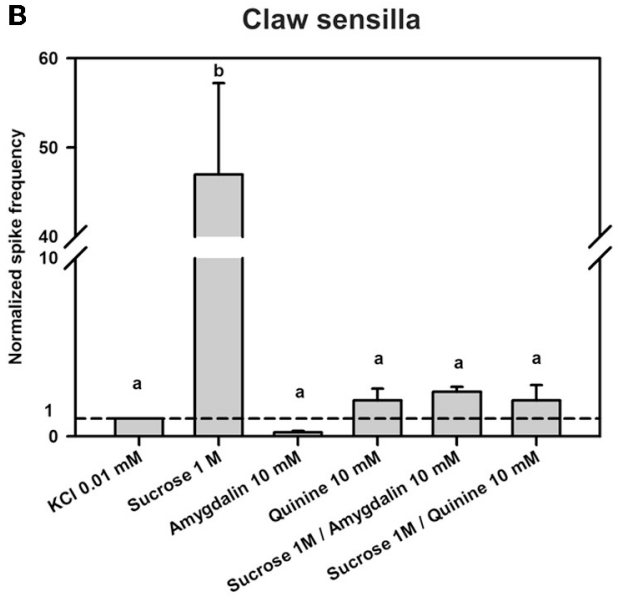

(B) Chaetic sensilla of the claws. Mean normalized spike frequencies $( \pm \mathrm{SE})$ obtained upon stimulation with the different tastants assayed. Responses (action potentials per second) were normalized to those recorded for $\mathrm{KCl} 0.01 \mathrm{mM}$ (hatched horizontal line). Data were obtained from 13 claw sensilla of 4 bees in response to the 6 stimuli assayed, each one being tested once $(n=78)$. Different letters above bars indicate significant differences $(p<0.05)$. 
A

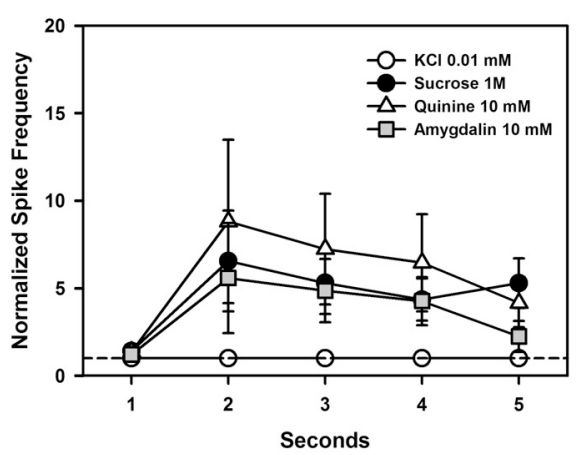

FIGURE 9 | Experiment 6. (A) Chaetic sensilla of the 3rd and 4th tarsomeres. Temporal analysis of mean normalized spike frequencies along five consecutive seconds of stimulation, starting at the onset and finishing at the offset of stimulation. The hatched line shows the reference response to the contact electrolyte $\mathrm{KCl} 0.01 \mathrm{mM}$. Besides $\mathrm{KCl}$, the curves show the temporal responses upon stimulation with sucrose $1 \mathrm{M}$, quinine $10 \mathrm{mM}$, and amygdalin $10 \mathrm{mM}$. There were significant differences between seconds of stimulation $(p<0.0005)$ but within each second, the responses obtained for the different tastants were statistically similar. (B) Chaetic sensilla of the claws. Temporal

\section{B Claw sensilla}

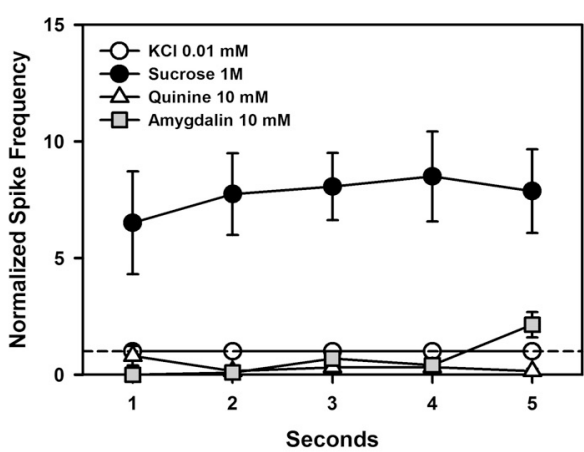

analysis of mean normalized spike frequencies along five consecutive seconds of stimulation, starting at the onset and finishing at the offset of stimulation. The hatched line shows the reference response to the contact electrolyte $\mathrm{KCl} 0.01 \mathrm{mM}$. Besides $\mathrm{KCl}$, the curves show the temporal responses upon stimulation with sucrose $1 \mathrm{M}$, quinine $10 \mathrm{mM}$, and amygdalin $10 \mathrm{mM}$. Responses varied significantly with the substance assayed as responses to sucrose $1 \mathrm{M}$ were higher than those to the other tastants all along the stimulation period $(p<0.0001)$. Differences were neither found for the factor "second" of stimulation nor for the interaction "substance $\times$ second". on tarsomere sensilla (see Figure 6B), which showed that quinine 1 and $10 \mathrm{mM}$, salicin $1 \mathrm{mM}$ and sucrose $1 \mathrm{M}$ yielded comparable pattern of responses as the contact electrolyte $\mathrm{KCl} 0.1 \mathrm{mM}$. With a more diluted contact electrolyte ( $\mathrm{KCl} 0.01 \mathrm{mM}$; Figure 9A), normalized responses were somehow higher (compare Figures 6B and 9A), yet undistinguishable from those obtained for the contact electrolyte. These results thus confirm the absence of bitter-tuned and sucrose-tuned receptor cells at the level of the tarsomere sensilla.

In the case of claw sensilla (Figure 9B), there were significant differences in cell responses to the substances assayed $\left[F_{(3,48)}=20.93, p<0.0001\right]$. Differences were neither found for the factor "second" of stimulation $\left[F_{(4,192)}=0.89, p=0.47\right]$ nor for the interaction "substance $\times$ second" $\left[F_{(12,192)}=1.05\right.$, $p=0.43]$. These results thus show that during the $5 \mathrm{~s}$ of stimulation, responses to sucrose were higher than those to other tastants. Responses to quinine and amygdalin were low and undistinguishable from those elicited by $\mathrm{KCl}$.

\section{DISCUSSION}

The tarsal taste of the honey bee has remained until now mostly unexplored (De Brito Sanchez, 2011) despite its long-claimed importance in taste detection (Frings and Frings, 1949). The present work provides the first integrative account on honey bee tarsal responses to sweet, salty, and bitter substances both at the behavioral and electrophysiological levels.

\section{BEHAVIORAL AND ELECTROPHYSIOLOGICAL SUCROSE RESPONSIVENESS}

Unilateral stimulation of the tarsi with sucrose (Figure 2) elicited PER in $60-70 \%$ of the cases (Figures $2 B-D$ ). These values contrast with those usually obtained upon antennal stimulation with sucrose (90-100\%). This disparity reflects the different sucrose sensitivities of these appendages (Marshall, 1935; De Brito Sanchez et al., 2008), which may be due to the fact that the tarsi are equipped with 15-30 times less receptors than the antennae (Whitehead and Larsen, 1976b).

The reciprocal experiment (Figures 3 and 4) showed that sucrose responsiveness was further decreased (PER was elicited in $20-40 \%$ of the cases) if a different substance was previously delivered to the tarsus opposite to that chosen for sucrose delivery. This decrease occurred irrespectively of the substance used as first tarsal stimulation. Water, for instance, induced the same decrease of sucrose responsiveness (Figure 3F) as quinine solution.

Experiments 1 and 2 suggest that responsiveness to sucrose in conditions of dual tarsal stimulation with sucrose and a different tastant depends on the primacy and nature of the tastant assayed. Sucrose solution delivered first elicits immediate PER which cannot then be inhibited by any other substance delivered afterwards on a different tarsus. In these conditions, sucrose acts as a "winner takes-all" stimulus. When a different tastant is first perceived by one tarsus, sucrose has no such effect when delivered to the other tarsus, thus showing that temporal primacy is also important. In this case, sucrose still elicits appetitive responses but these are significantly diminished, thus revealing an unspecific central inhibition. This indicates that a process of central integration takes place, probably at the level of the thoracic ganglion. Because different legs were used in these experiments, differences in responses can only be due to gustatory crosscomparison and inhibition between opposite tarsi (Dethier and Bowdan, 1992). In this process, two principles can be identified: (1) primacy is acquired by the first arriver and (2) asymmetries exist between sucrose and bitter/watery substances so that the 
former partially overcomes inhibition by the latter but not reciprocally. Further electrophysiological and behavioral experiments may help uncovering the mechanisms of this central inhibition.

Our electrophysiological recordings revealed that chaetic sensilla of the claws and of the tarsomeres differed in their response to sucrose solution $1 \mathrm{M}$. Tarsomere sensilla responded to sucrose solution in a similar way as to the contact electrolyte $\mathrm{KCl}$ (Figures 6A, 8A). Our attempt to establish a dose-response curve for sucrose in the case of tarsomere sensilla was not successful as there was no increase of cell responses with sucrose concentration over three orders of magnitude (Figure 7C). These results indicate that tarsomere sensilla do not host a sucrose receptor cell. On the contrary, claw sensilla responded 40-50 times more to sucrose $1 \mathrm{M}$ than to $\mathrm{KCl}$ (Figure 8B). In these sensilla, temporal responses were always higher for sucrose than for other tastants assayed (Figure 9B). These results thus show that claw sensilla host a sucrose receptor cell and that the claws are the sucrose detecting region of the tarsi.

These conclusions were confirmed by the different responses obtained upon stimulation with mixtures of sucrose and bitter substances: while tarsomeres sensilla responded similarly to sucrose and to mixtures of sucrose and bitter substances (see Figure 8A), claw sensilla exhibited a significant reduction of responsiveness upon mixture stimulation (see Figure $\mathbf{8 B}$ ). This reduction is consistent with the know inhibitory effect of bitter substances on sucrose receptor cells (Bernays and Chapman, 2000, 2001; De Brito Sanchez et al., 2005; Cocco and Glendinning, 2012).

\section{BEHAVIORAL AND ELECTROPHYSIOLOGICAL BITTER RESPONSIVENESS}

Four substances that are perceived as bitter by humans-quinine, salicin, caffeine, and amygdalin - and that induce avoidance in the fruit fly (Meunier et al., 2003; Hiroi et al., 2004; Thorne et al., 2004; Wang et al., 2004; Marella et al., 2006; Masek and Scott, 2010) and in other insects (e.g., Chapman et al., 1991; Dethier and Bowdan, 1992; Ramaswamy et al., 1992; Bowdan, 1995) did neither inhibit appetitive responses in harnessed bees nor were detected via specific tarsal receptors. Different concentrations of these substances were unable to induce proboscis retraction once PER was elicited by sucrose (Figure 2). Two main explanations are possible: either peripheral detection of bitter taste is not possible via the tarsi, similarly to what happens with the antennae (De Brito Sanchez et al., 2005), or if it is possible, it is outweighed by sucrose stimulation so that the threshold for eliciting PER to sucrose would be lower than that for eliciting proboscis retraction to aversive substances.

Irrespectively of the concentration used, bitter substances delivered to one tarsus were unable to repress PER if sucrose was delivered to other fore tarsus, even if a lower level of PER was observed in these cases (Figures 3 and 4). Such decrease was induced not only by aversive substances but also by water, and was observable in bees which had their antennae intact or amputated. These results exclude both the lesion and the potential aversive nature of the first stimulation as a causal factor of the decrease in sucrose responsiveness. As mentioned above, the fact that sucrose responsiveness decreased when a different substance was first delivered in the leg opposite to the one used for sucrose stimulation speaks in favor of a central inhibitory process. Moreover, the fact that water yielded the same pattern of responses as concentrated quinine solution confirms that tarsal sensitivity for bitter substances is rather limited. Only, the lower level of PER induced by salicin upon sucrose stimulation compared to quinine solution and water (Figure 3F) indicates some inhibitory effect of salicin per se.

We were unable to detect specific electrophysiological responses to quinine, salicin, and amygdalin in electrophysiological recordings of chaetic sensilla located both on the tarsomeres and claws of the fore legs. The responses to bitter substances recorded at the level of tarsomere sensilla were, in fact, responses of a gustatory receptor cell triggered by the contact electrolyte $\mathrm{KCl}(0.1 \mathrm{mM})$. The fact that in these sensilla, no variations in responses to quinine were recorded over 3 orders of magnitude (Figure 7B) confirmed the absence of a cell tuned to this bitter substance in the tarsomeres.

The lack of an evident aversive effect of bitter substances is consistent with the report of von Frisch who mentioned that bitter solutions have no noticeable effect on the bees' ingestion of sugar solutions (Von Frisch, 1967). This may be due to the fact that sugars may mask bitter substances (Glendinning, 2002; Cocco and Glendinning, 2012). However, low concentrations of bitter substances such as phenolics and alkaloids in sucrose solution or nectar enhance food attractiveness while unnatural high concentrations of these substances diminish it (Hagler and Buchmann, 1993; Liu et al., 2004; Singaravelan et al., 2006; Liu et al., 2007). How are these differences detected in the light of an apparent absence of bitter receptors? Several explanations are possible: (1) such receptors exist but are neither located in the antennae (De Brito Sanchez et al., 2005) nor in the tarsi (this work); (2) responding aversively to bitter substances depends on the possibility of freely expressing avoidance; this is possible for freeflying bees but not for immobilized bees such as those used in our experiments (see discussion of this argument in Ayestaran et al., 2010); (3) detecting bitter components in nectar is possible via an indirect mechanism, namely the inhibition of sucrose receptors by bitter substances when these molecules appear together in a compound, such as in nectar with high levels of caffeine (Singaravelan et al., 2006). Inhibition of sucrose receptors by mixtures of either quinine and sucrose or amygdalin and sucrose was observed in claw sensilla (Figure 9B). This mechanism was also shown for sucrose receptors on the antennae of the honey bee (De Brito Sanchez et al., 2005) and for tarsal sucrose receptors of Drosophila (Meunier et al., 2003), blowflies (Dethier and Bowdan, 1989) and moth caterpillars (Bernays and Chapman, 2000, 2001), which are inhibited by several alkaloids and other substances that are bitter for humans.

\section{ELECTROPHYSIOLOGICAL SALT RESPONSIVENESS}

Chaetic sensilla on the tarsomeres exhibited high responsiveness to $\mathrm{NaCl} 100 \mathrm{mM}$ (Figure 6A). These sensilla thus host at least one receptor neuron highly responding to salts. This finding is in agreement with the well-documented preference of water foragers for salty water over pure water (Butler, 1940; Kiechle, 1961; Von Frisch, 1967). The reasons for such preference are unclear. It 
is assumed that bees prefer salty waters as they obtain from them minerals that are used for their own metabolism and for larval development (Dietz, 1971). But to our knowledge, no experiment has measured where and how bees do metabolize the salts collected during water foraging.

High sensitivity to saline solutions was also supported by the fact that tarsomere sensilla responded to extremely low $\mathrm{KCl}$ concentrations. In experiments 3 and 5, the contact electrolyte chosen was $\mathrm{KCl} 0.1 \mathrm{mM}$ because higher concentrations of $\mathrm{KCl}$ (e.g., $10 \mathrm{mM}$ ) have been used in previous works as contact electrolyte to study gustatory responses in other appendages such as the antennae of bees and moths without inducing significant neural activity (De Brito Sanchez et al., 2005; Jørgensen et al., 2007). Yet, KCl $0.1 \mathrm{mM}$ induced significant activity (Figures 5A, 6A). Tarsomere sensilla host at least a $\mathrm{KCl}$ receptor cell because spike frequency increased significantly with $\mathrm{KCl}$ concentration, especially in the range of low concentrations (Figure 7A). This increase is incompatible with the response of a water receptor cell and indicated that some responses to tastants were in fact responses to the diluted $\mathrm{KCl}$ used as contact electrolyte rather than to the tastants themselves. In Drosophila melanogaster, most taste sensilla house four gustatory receptor neurons, one of which is maximally sensitive to salt at low concentrations (L1 cell) (Meunier et al., 2003; Hiroi et al., 2004). The $\mathrm{KCl}$ cell reported in our work could therefore act as the equivalent of the L1 cell.

Contrarily to sucrose sensitivity, saline sensitivity was higher on the tarsi than on the antennae as shown by the difference of three orders of magnitude between the concentrations of $\mathrm{KCl}$ used as efficient contact electrolytes in either case $[10 \mathrm{mM}$ for the antennae (De Brito Sanchez et al., 2005) and $0.01 \mathrm{mM}$ for the tarsi]. This difference may have an adaptive value: while sucrose is usually hidden in flower nectaries, thus requiring antennal assessment and not necessarily a direct contact with the tarsi, water surfaces are plain and are probably first contacted by the tarsi of a hovering bee to evaluate salt contents before making a decision on whether engaging or not in water collection.

\section{CONCLUSION}

Our results provide an integrative view of gustatory tarsal detection in the honey bee, where the gustatory modality has received less attention than other modalities such as vision or olfaction (De Brito Sanchez, 2011) and where, in particular, the gustatory role of the tarsi has not been studied in detail.

Two main lines of future research emerge from our findings. On the one hand, it is imperative to provide a better characterization of molecular gustatory receptors present on single gustatory receptor cells hosted in gustatory sensilla of the tarsi. The genome of the honey bee (The Honeybee Genome Sequencing Consortium, 2006) has uncovered the presence of only 10 gustatory receptors genes (Grs; Robertson and Wanner, 2006) whose ligands are still unknown. It has been suggested that at least two of the bee Grs share homologies with the Drosophila Grs tuned to respond to sugars (Robertson and Wanner, 2006). Consistently with our findings, none of the bee Grs shows homologies with the different fly Grs specialized in bitter taste detection (Robertson and Wanner, 2006), which seems to be a general characteristic of Hymenoptera irrespective of their feeding style (e.g., ants;
Bonasio et al., 2010). A fundamental task is therefore to identify the ligands and specificities of the Grs existing in the honey bee.

On the other hand, our results indicate that gustatory information from different legs is subjected to cross-comparison and can trigger, depending on which kind of taste is first perceived, a central excitatory state (sucrose 1st, non-sucrose 2 nd) or a central inhibitory state (non-sucrose 1 st, sucrose $2 \mathrm{nd}$ ). This result raises the question of the mechanisms of central taste processing, for instance at the level of the thoracic ganglion where information from opposite tarsi converges. Further studies such as those performed in the thoracic ganglia of the locust (Newland et al., 2000a,b; Rogers and Newland, 2002), an insect that exhibits a taste sensitivity different from that of the honey bee given the presence of tarsal cell receptors tuned to bitter substances, should analyze how tarsal gustatory input is processed at the central level.

Finally, the fact that the taste modality has been relatively neglected compared to other modalities such as vision and olfaction, which have been intensively studied in the honey bee (Galizia et al., 2011), makes necessary a focus on taste perception through other body appendages besides the tarsi. As we have already characterized antennal taste perception (De Brito Sanchez et al., 2005), a next step is to provide an integrative study of taste perception at the level of the mouth parts. Contrarily to antennal and tarsal taste, for which previous studies were very scarce, taste via the mouth parts has been the subject of some detailed studies (Whitehead and Larsen, 1976a,b; Whitehead, 1978). Yet, the information obtained on antennal and tarsal taste receptors allows asking new questions. For instance, do antennal and tarsal taste receptors share the same gustatory logics with those of the mouth parts? Future work will allow answering this and other related questions.

\section{ACKNOWLEDGMENTS}

We thank two anonymous reviewers for comments and corrections on a previous version of our manuscript. This work was supported by the University Paul Sabatier (Travel Grants to Maria Gabriela de Brito Sanchez and Martin Giurfa), the CNRS, The Institut Universitaire de France (Martin Giurfa), the Xishuangbanna Tropical Botanic Garden, Chinese Academy of Sciences (Fanglin Liu) and Zhejiang University (Songkun Su).

\section{REFERENCES}

Ayestaran, A., Giurfa, M., and De Brito Sanchez, M. G. (2010). Toxic but drank: gustatory aversive compounds induce post-ingestional malaise in harnessed honeybees. PLoS ONE 5:e15000. doi: 10.1371/journal.pone.0015000

Bernays, E. A., and Chapman, R. F. (2000). A neurophysiological study of sensitivity to a feeding deterrent in two sister species of Heliothis with different diet breadths. J. Insect Physiol. 46, 905-912. doi: 10.1016/S0022-1910(99)00197-3

Bernays, E. A., and Chapman, R. F. (2001). Electrophysiological responses of taste cells to nutrient mixtures in the polyphagous caterpillar of Grammia geneura. J. Comp. Physiol. A 187, 205-213. doi: 10.1007/s003590100191

Bonasio, R., Zhang, G., Ye, C., Mutti, N. S., Fang, X., Qin, N., et al. (2010). Genomic comparison of the ants Camponotus floridanus and Harpegnathos saltator. Science 329, 1068-1071. doi: 10.1126/science.1192428

Bowdan, E. (1995). The effects of a phagostimulant and a deterrent on the microstructure of feeding by Manduca sexta caterpillars. Entomol. Exp. Appl. 77 297-306. doi: 10.1111/j.1570-7458.1995.tb02327.x

Butler, C. G. (1940). The choice of drinking water by the honeybee. J. Exp. Biol. 17, 253-261. 
Carleton, A., Accolla, R., and Simon, S. A. (2010). Coding in the mammalian gustatory system. Trends Neurosci. 33, 326-334. doi: 10.1016/j.tins.2010.04.002

Chapman, R. F., Ascoli-Christensen, A., and White, P. R. (1991). Sensory cording for feeding deterrence in the grasshopper Schistocerca americana. J. Exp. Biol. 158, 241-259.

Clyne, P. J., Warr, C. G., and Carlson, J. R. (2000). Candidate taste receptors in Drosophila. Science 287, 1830-1834. doi: 10.1126/science.287.5459.1830

Cobb, M., Scott, K., and Pankratz, M. (2009). Gustation in Drosophila melanogaster. SEB Exp. Biol. Ser. 63, 1-38.

Cocco, N., and Glendinning, J. I. (2012). Not all sugars are created equal: some mask aversive tastes better than others in an herbivorous insect. J. Exp. Biol. 215, 1412-1421. doi: 10.1242/jeb.0 59832

Dahanukar, A., Hallem, E. A., and Carlson, J. R. (2005). Insect chemoreception. Curr. Opin. Neurobiol. 15, 423-430. doi: 10.1016/j.conb.2005.06.001

De Brito Sanchez, M. G. (2011). Taste perception in honey bees. Chem. Senses 36, 675-692. doi: 10.1093/chemse/bjr040

De Brito Sanchez, M. G., Chen, C., Li, J., Liu, F., Gauthier, M., and Giurfa, M. (2008). Behavioral studies on tarsal gustation in honeybees: sucrose responsiveness and sucrose-mediated olfactory conditioning. J. Comp. Physiol. A 194, 861-869. doi: 10.1007/s00359-008-0357-8

De Brito Sanchez, M. G., and Giurfa, M. (2011). A comparative analysis of neural taste processing in animals. Philos. Trans. R. Soc. Lond. B Biol. Sci. 366, 2171-2180. doi: 10.1098/rstb.2010.0327

De Brito Sanchez, M. G., Giurfa, M., De Paula Mota, T. R., and Gauthier, M. (2005). Electrophysiological and behavioural characterization of gustatory responses to antennal 'bitter' taste in honeybees. Eur. J. Neurosci. 22, 3161-3170. doi: 10.1111/j.1460-9568.2005.04516.x

Dethier, V. G., and Bowdan, E. (1989). The effect of alkaloids on the sugar receptors of the blowfly. Physiol. Entomol. 14, 127-136. doi: 10.1111/j.13653032.1989.tb00944.x

Dethier, V. G., and Bowdan, E. (1992). Effects of alkaloids on feeding by Phormia regina confirm the critical role of sensory inhibition. Physiol. Entomol. 17, 325-330. doi: 10.1111/j.1365-3032.1992.tb01030.x

Dietz, A. (1971). Changes with age in some mineral constituents of worker honey bees, I. Phosphorus, potassium, calcium, magnesium, sodium and iron. J. Ga. Entomol. Soc. 6, 54-57.

Dunipace, L., Meister, S., McNealy, C., and Amrein, H. (2001). Spatially restricted expression of candidate taste receptors in the Drosophila gustatory system. Curr. Biol. 2001, 822-835. doi: 10.1016/S0960-9822(01)00258-5

Frings, H., and Frings, M. (1949). The loci of contact chemoreceptors in insects. A review with new evidence. Am. Mid. Nat. 41, 602-658. doi: 10.2307/2421776

Galizia, C., Eisenhardt, D., and Giurfa, M. (2011). Honeybee Neurobiology and Behavior: A Tribute to Randolf Menzel. Berlin: Springer.

Giurfa, M. (2007). Behavioral and neural analysis of associative learning in the honeybee: a taste from the magic well. J. Comp. Physiol. A 193, 801-824. doi: 10.1007/s00359-007-0235-9

Glendinning, J. I. (2002). How do herbivorous insects cope with noxious secondary plant compounds in their diet? Entomol. Exp. Appl. 104, 15-25. doi: 10.1046/j.1570-7458.2002.00986.x

Goodman, L. (2003). Form and Function in the Honey Bee. Cardiff: IBRA.

Hagler, J. R., and Buchmann, S. L. (1993). Honey-bee (Hymenoptera, Apidae) foraging responses to phenolic-rich nectars. J. Kansas Entomol. Soc. 66, 223-230.

Hallem, E. A., Dahanukar, A., and Carlson, J. R. (2006). Insect odor and taste receptors. Annu. Rev. Entomol. 51, 113-135. doi: 10.1146/annurev.ento.51.051705.113646

Haupt, S. S. (2004). Antennal sucrose perception in the honey bee (Apis mellifera L.): behaviour and electrophysiology. J. Comp. Physiol. A 190, 735-745. doi: 10.1007/s00359-004-0532-5

Hiroi, M., Meunier, N., Marion-Poll, F., and Tanimura, T. (2004). Two antagonistic gustatory receptor neurons responding to sweet-salty and bitter taste in Drosophila. J. Neurobiol. 61, 333-342. doi: 10.1002/neu. 20063

Ishimoto, H., and Tanimura, T. (2004). Molecular neurophysiology of taste in Drosophila. Cell. Mol. Life Sci. 61, 10-18. doi: 10.1007/s00018-003-3182-9

Jørgensen, K., Almaas, T. J., Marion-Poll, F., and Mustaparta, H. (2007). Electrophysiological characterization of responses from gustatory receptor neurons of sensilla chaetica in the moth Heliothis virescens. Chem. Senses 32, 863-879. doi: 10.1093/chemse/bjm057
Kessler, S., Vlimant, M., and Guerin, P. (2012). The sugar meal of the African malaria mosquito Anopheles gambiae and how deterrent compounds interfere with it: a behavioural and neurophysiological syudy. J. Exp. Biol. 216, 1292-1306. doi: 10.1242/jeb.076588

Kiechle, H. (1961). Die soziale Regulation der Wassersammeltatigkeit im Bienenstaat und deren physiologische Grundlage. Z. vergl. Physiol. 45, 154-192. doi: $10.1007 / \mathrm{BF} 00297763$

Kuwabara, M. (1957). Bildung des bedingten Reflexes von Pavlovs Typus bei der Honigbiene, Apis mellifica. J. Fac. Sci. Hokkaido Univ. Ser. VI Zool. 13, 458-464.

Liu, F., Chen, J., Chai, J., Zhang, X., Bai, X., He, D., et al. (2007). Adaptive functions of defensive plant phenolics and a non-linear bee response to nectar components. Funct. Ecol. 21, 96-100. doi: 10.1111/j.1365-2435.2006.01200.x

Liu, F., Fu, W. J., Yang, D. R., Peng, Y. Q., Zhang, X. W., and He, J. Z. (2004). Reinforcement of bee-plant interaction by phenolics in food. J. Apic. Res. 43, 155-157.

Marella, S., Fischler, W., Kong, P., Asgarian, S., Rueckert, E., and Scott, K. (2006). Imaging taste responses in the fly brain reveals a functional map of taste category and behavior. Neuron 49, 285-295. doi: 10.1016/j.neuron.2005. 11.037

Marshall, J. (1935). On the sensitivity of the chemoreceptors on the antenna and fore-tarsus of the honey-bee, Apis mellifica L. J. Exp. Biol. 12, 17-26.

Masek, P., and Scott, K. (2010). Limited taste discrimination in Drosophila. Proc. Natl. Acad. Sci. U.S.A. 107, 14833-14838. doi: 10.1073/pnas.10093 18107

Meunier, N., Marion-Poll, F., Rospars, J. P., and Tanimura, T. (2003). Peripheral coding of bitter taste in Drosophila. J. Neurobiol. 56, 139-152. doi: 10.1002/neu. 10235

Montell, C. (2009). A taste of the Drosophila gustatory receptors. Curr. Opin. Neurobiol. 19, 345-353. doi: 10.1016/j.conb.2009.07.001

Newland, P. L., Rogers, S. M., Gaaboub, I., and Matheson, T. (2000a). Parallel somatotopic maps of gustatory and mechanosensory neurons in the central nervous system of an insect. J. Comp. Neurol. 425, 82-96. doi: 10.1002/10969861(20000911)425:1<82::AID-CNE8>3.0.CO;2-5

Newland, P. L., Rogers, S. M., Matheson, T., and Gaaboub, I. (2000b). Overlapping chemosensory and mechanosensory maps in the thoracic ganglia of the locust. Eur. J. Neurosci. 12, 498.

Ramaswamy, S. B., Cohen, N. E., and Hanson, F. E. (1992). Deterrence of feeding and oviposition responses of adult Heliothis virescens by some compounds bitter-tasting to humans. Entomol. Exp. Appl. 65, 81-93. doi: 10.1111/j.15707458.1992.tb01630.x

Robertson, H. M., and Wanner, K. W. (2006). The chemoreceptor superfamily in the honey bee, Apis mellifera: expansion of the odorant, but not gustatory, receptor family. Genome Res. 16, 1395-1403. doi: 10.1101/gr.50 57506

Robertson, H. M., Warr, C. G., and Carlson, J. R. (2003). Molecular evolution of the insect chemoreceptor gene superfamily in Drosophila melanogaster. Proc. Natl. Acad. Sci. U.S.A. 100, 14537-14542. doi: 10.1073/pnas.2335847100

Rogers, S. M., and Newland, P. L. (2002). Gustatory processing in thoracic local circuits of locusts. J. Neurosci. 22, 8324-8333.

Scott, K. (2004). The sweet and the bitter of mammalian taste. Curr. Opin. Neurobiol. 14, 423-427. doi: 10.1016/j.conb.2004.06.003

Scott, K. (2005). Taste recognition: food for thought. Neuron 48, 455-464. doi: 10.1016/j.neuron.2005.10.015

Scott, K., Brady, R., Cravchik, A., Morozov, P., Rzhetsky, A., Zuker, C., et al. (2001). A chemosensory gene family encoding candidate gustatory and olfactory receptors in Drosophila. Cell 104, 661-673. doi: 10.1016/S0092-8674(01)00 263-X

Singaravelan, N., Inbar, M., Ne'eman, G., Distl, M., Wink, M., and Izhaki, I. (2006). The effects of nectar-nicotine on colony fitness of caged honeybees. J. Chem. Ecol. 32, 49-59. doi: 10.1007/s10886-006-9350-2

Snodgrass, R. E. (1956). Anatomy of the Honey Bee. New York, NY: Comstock Publishing Associates.

The Honeybee Genome Sequencing Consortium. (2006). Insights into social insects from the genome of the honeybee Apis mellifera. Nature 443, 931-949. doi: 10.1038/nature05260

Thorne, N., Chromey, C., Bray, S., and Amrein, H. (2004). Taste perception and coding in Drosophila. Curr. Biol. 14, 1065-1079. doi: 10.1016/j.cub.2004.05.019

Von Frisch, K. (1967). The Dance Language and Orientation of Bees. Cambridge: Harvard University Press. 
Vosshall, L. B., and Stocker, R. E. (2007). Molecular architecture of smell and taste in Drosophila. Annu. Rev. Neurosci. 30, 505-533. doi: 10.1146/annurev.neuro.30.051606.094306

Wang, Z. R., Singhvi, A., Kong, P., and Scott, K. (2004). Taste representations in the Drosophila brain. Cell 117, 981-991. doi: 10.1016/j.cell.2004.06.011

Whitehead, A. T. (1978). Electrophysiological response of honey bee labial palp contact chemoreceptors to sugars and electrolytes. Physiol. Entomol. 3, 241-248. doi: 10.1111/j.1365-3032.1978.tb00153.x

Whitehead, A. T., and Larsen, J. R. (1976a). Electrophysiological responses of galeal contact chemoreceptors of Apis mellifera to selected sugars and electrolytes. J. Insect Physiol. 22, 1609-1616. doi: 10.1016/0022-1910(76)90052-4

Whitehead, A. T., and Larsen, J. R. (1976b). Ultrastructure of the contact chemoreceptors of Apis mellifera L. (Hymenoptera: Apidae). Int. J. Insect Morphol. Embryol. 5, 301-315. doi: 10.1016/0020-7322(76)90030-1

Yarmolinsky, D. A., Zuker, C. S., and Ryba, N. J. (2009). Common sense about taste: from mammals to insects. Cell 139, 234-244. doi: 10.1016/j.cell.2009.10.001
Conflict of Interest Statement: The authors declare that the research was conducted in the absence of any commercial or financial relationships that could be construed as a potential conflict of interest.

Received: 07 December 2013; accepted: 16 January 2014; published online: 04 February 2014.

Citation: de Brito Sanchez MG, Lorenzo E, Su S, Liu F, Zhan Y and Giurfa M (2014) The tarsal taste of honey bees: behavioral and electrophysiological analyses. Front. Behav. Neurosci. 8:25. doi: 10.3389/fnbeh.2014.00025

This article was submitted to the journal Frontiers in Behavioral Neuroscience. Copyright (C) 2014 de Brito Sanchez, Lorenzo, Su, Liu, Zhan and Giurfa. This is an open-access article distributed under the terms of the Creative Commons Attribution License (CC BY). The use, distribution or reproduction in other forums is permitted, provided the original author(s) or licensor are credited and that the original publication in this journal is cited, in accordance with accepted academic practice. No use, distribution or reproduction is permitted which does not comply with these terms. 